Supporting Information For:

$\mathrm{SO}_{2} \mathrm{~F}_{2}$-Mediated Epoxidation of Olefins with Hydrogen Peroxide

Chengmei Ai, Fuyuan Zhu, Yanmei Wang, Zhaohua Yan,* Sen Lin*

list of Contents

S1. ${ }^{1} \mathrm{H}$ and ${ }^{13} \mathrm{C}$ NMR

spectra

$\mathrm{S} 2$ 


\section{S1. $\quad{ }^{1} \mathrm{H}$ and ${ }^{13} \mathrm{C}$ NMR spectra}

3-Phenyl-2-oxiranemethanol (2a)

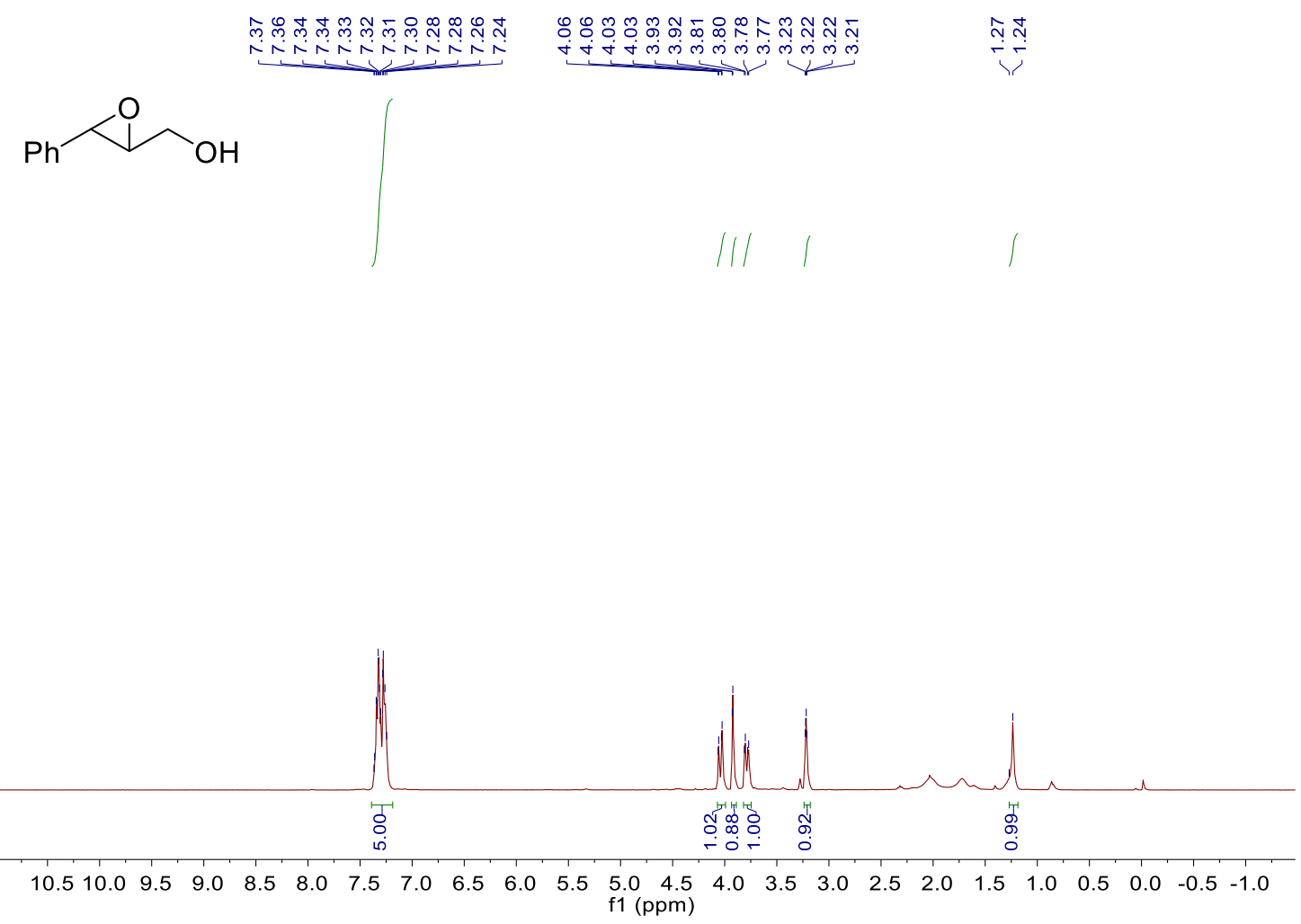


<smiles>OCC1OC1c1ccccc1</smiles>
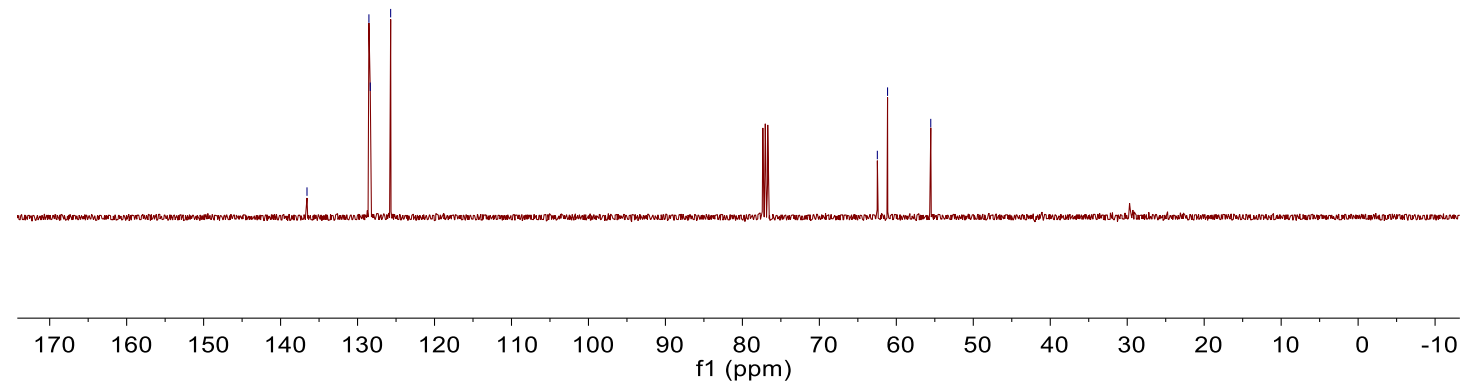

2-Octyloxirane (2b)

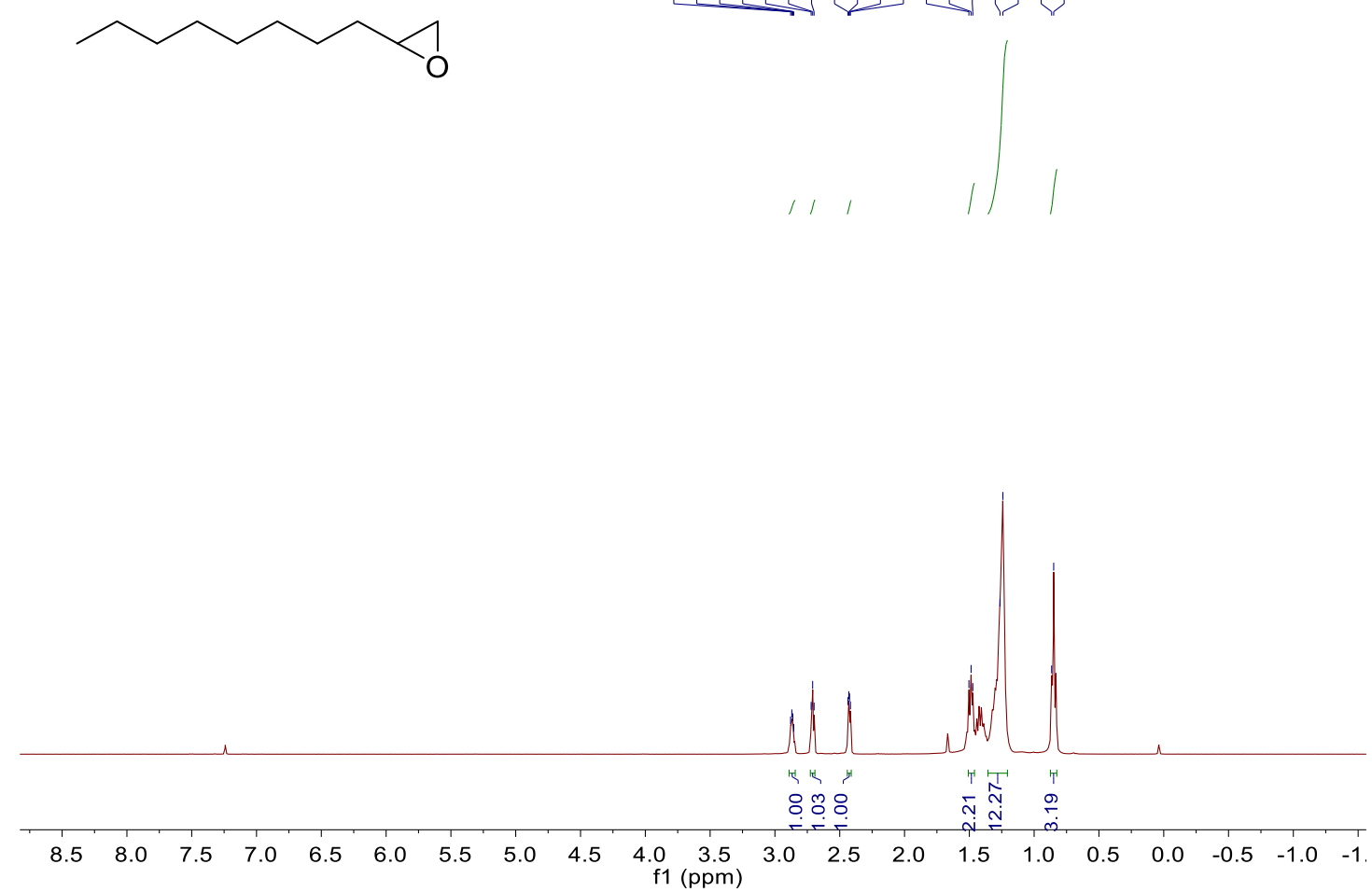

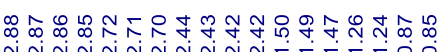

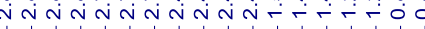



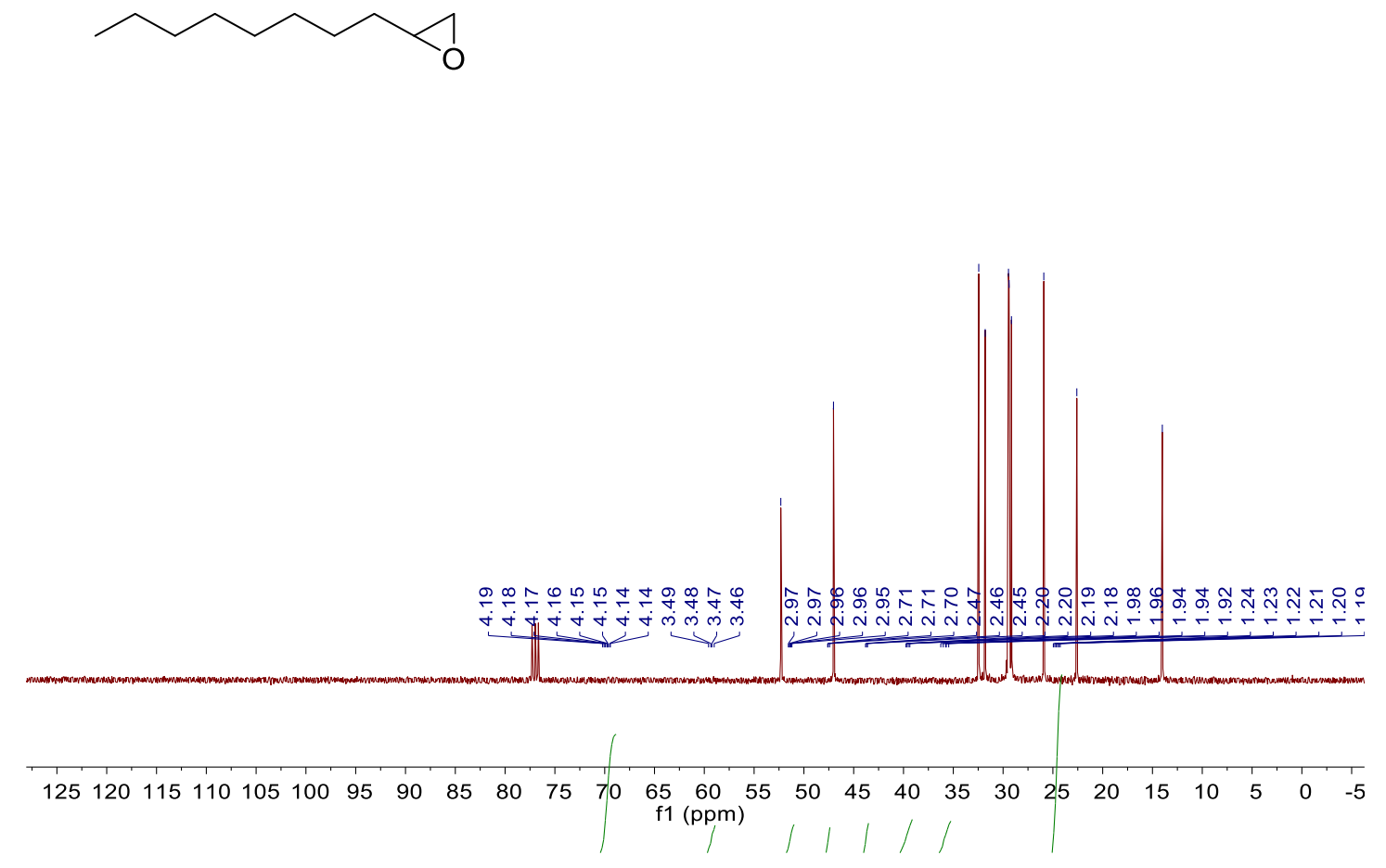

Diethyl 2-(oxiran-2-ylmethyl)propanedioate (2c)

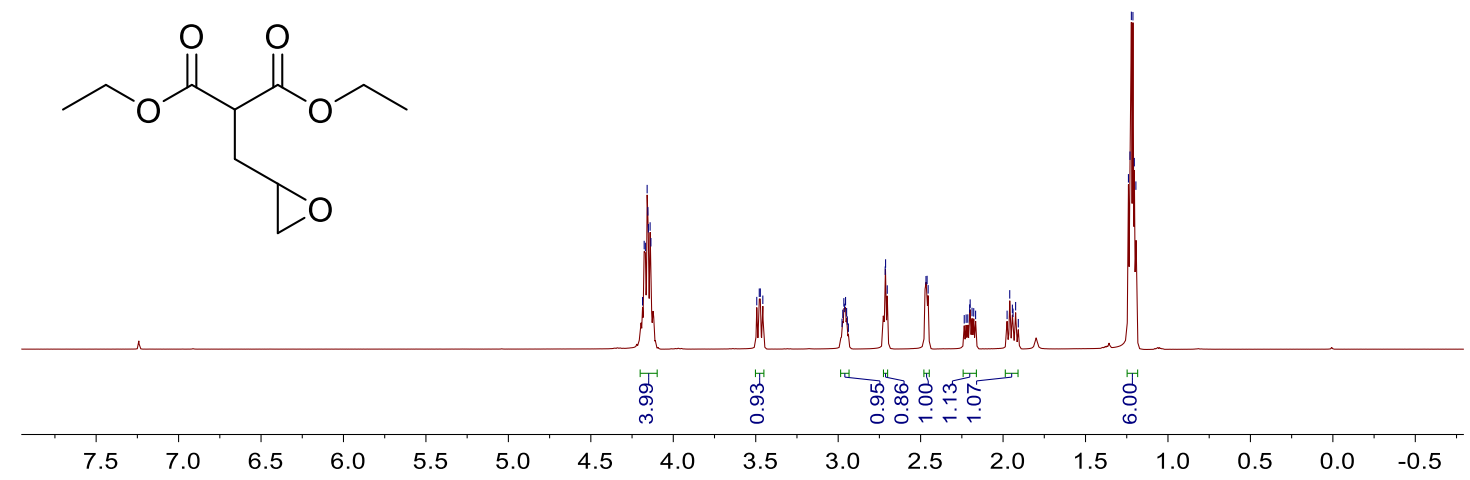




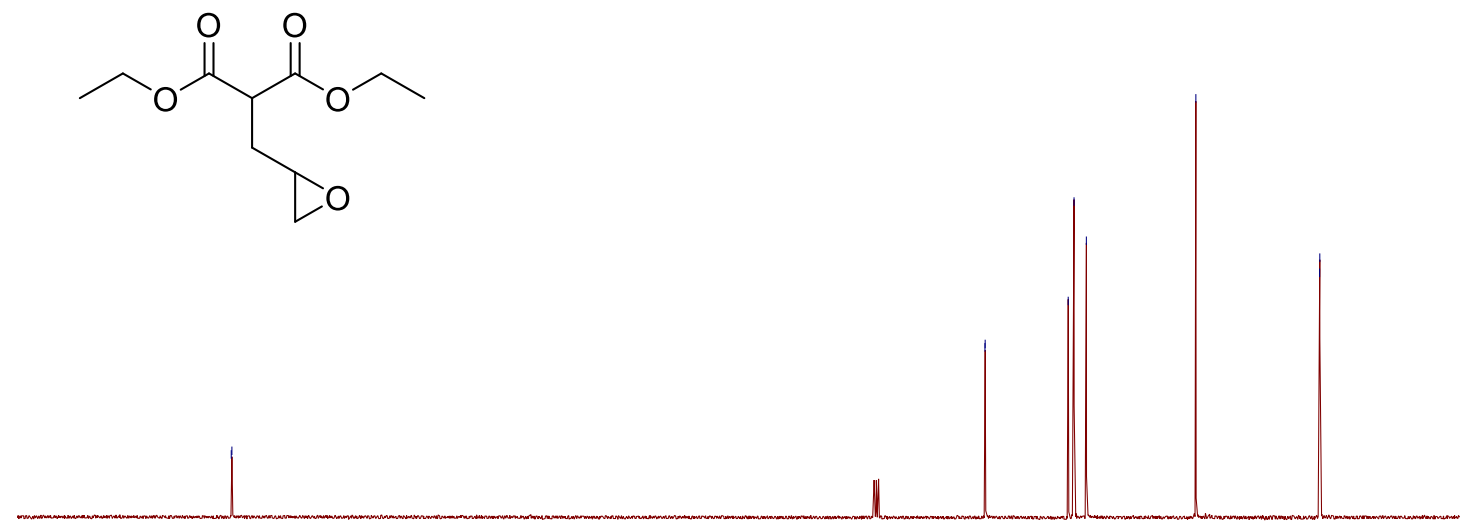

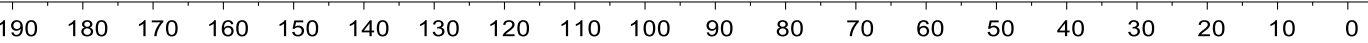

Oxiran-2-ylmethyl 3-cyclohexylpropanoate (2d)

m

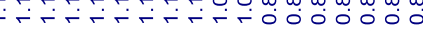<smiles>O=C(CCC1CCCCC1)OCC1CO1</smiles>

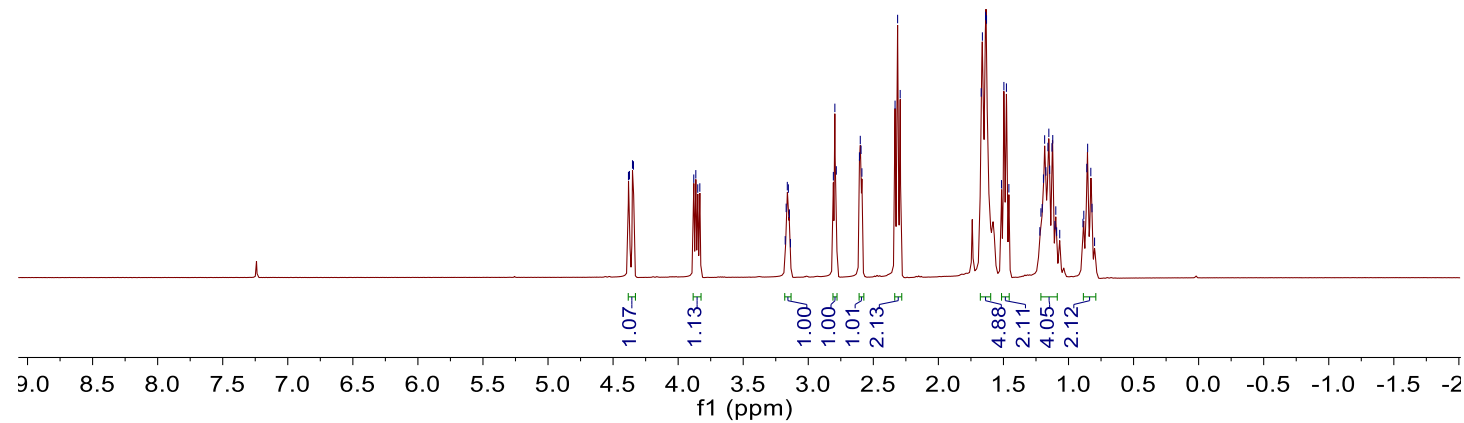


<smiles>O=C(CCC1CCCCC1)OCC1CO1</smiles>

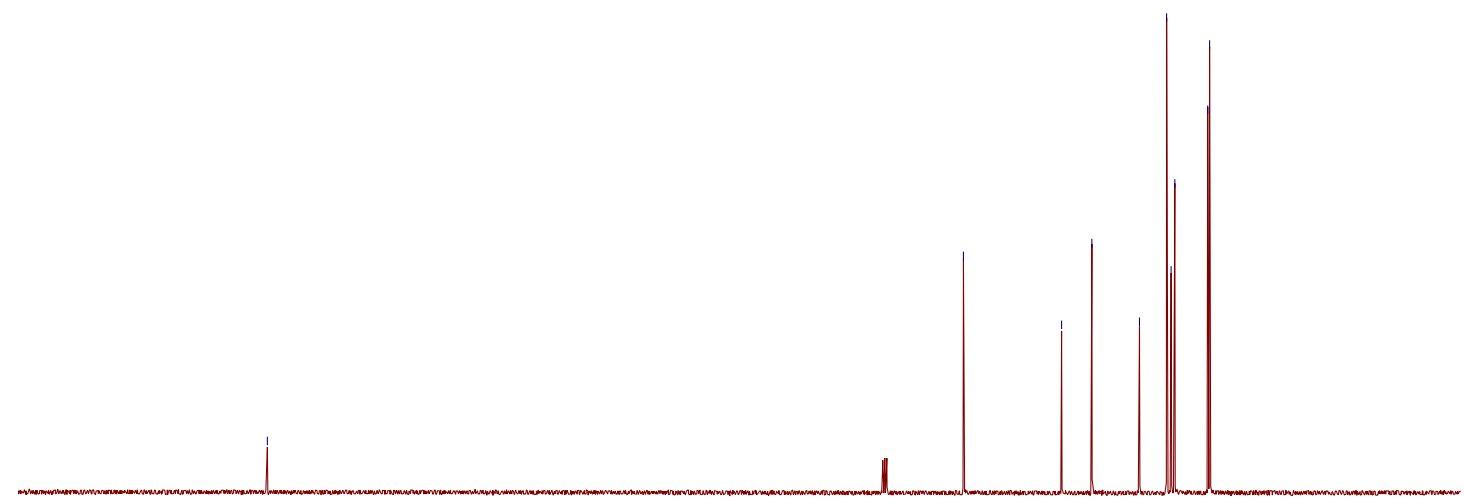

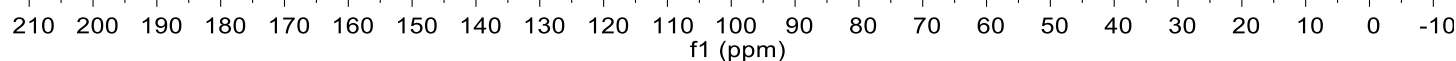

2-[(Phenylmethoxy)methyl]oxirane (2e)

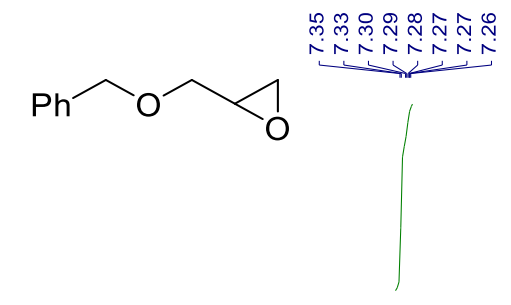

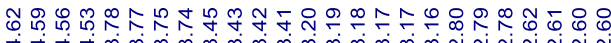

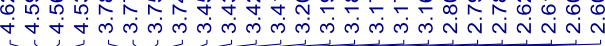

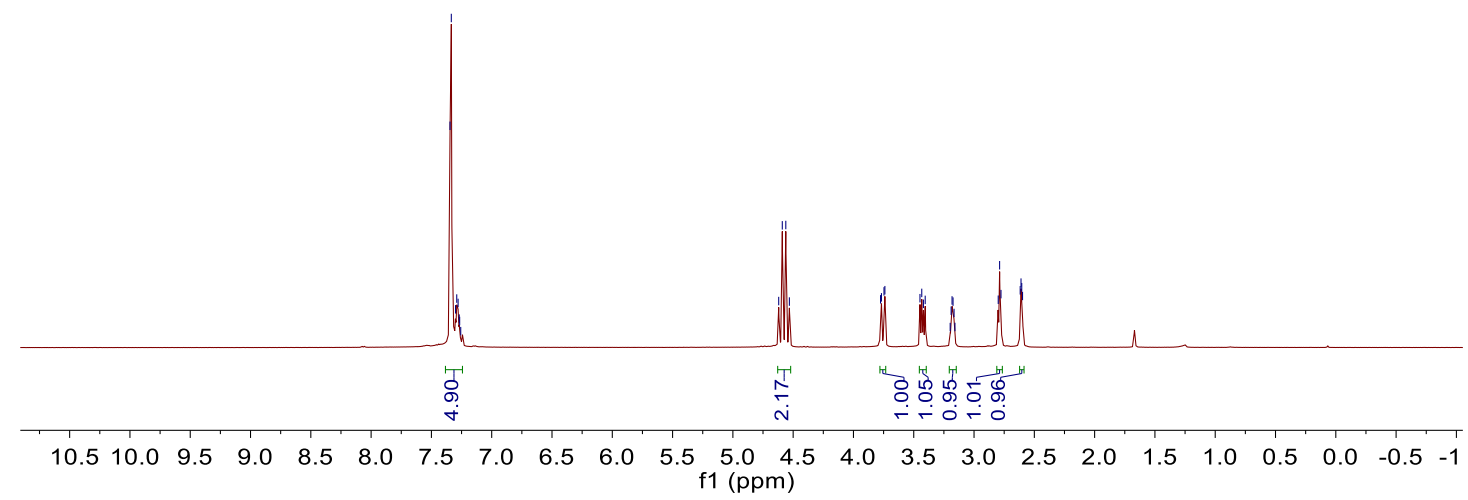



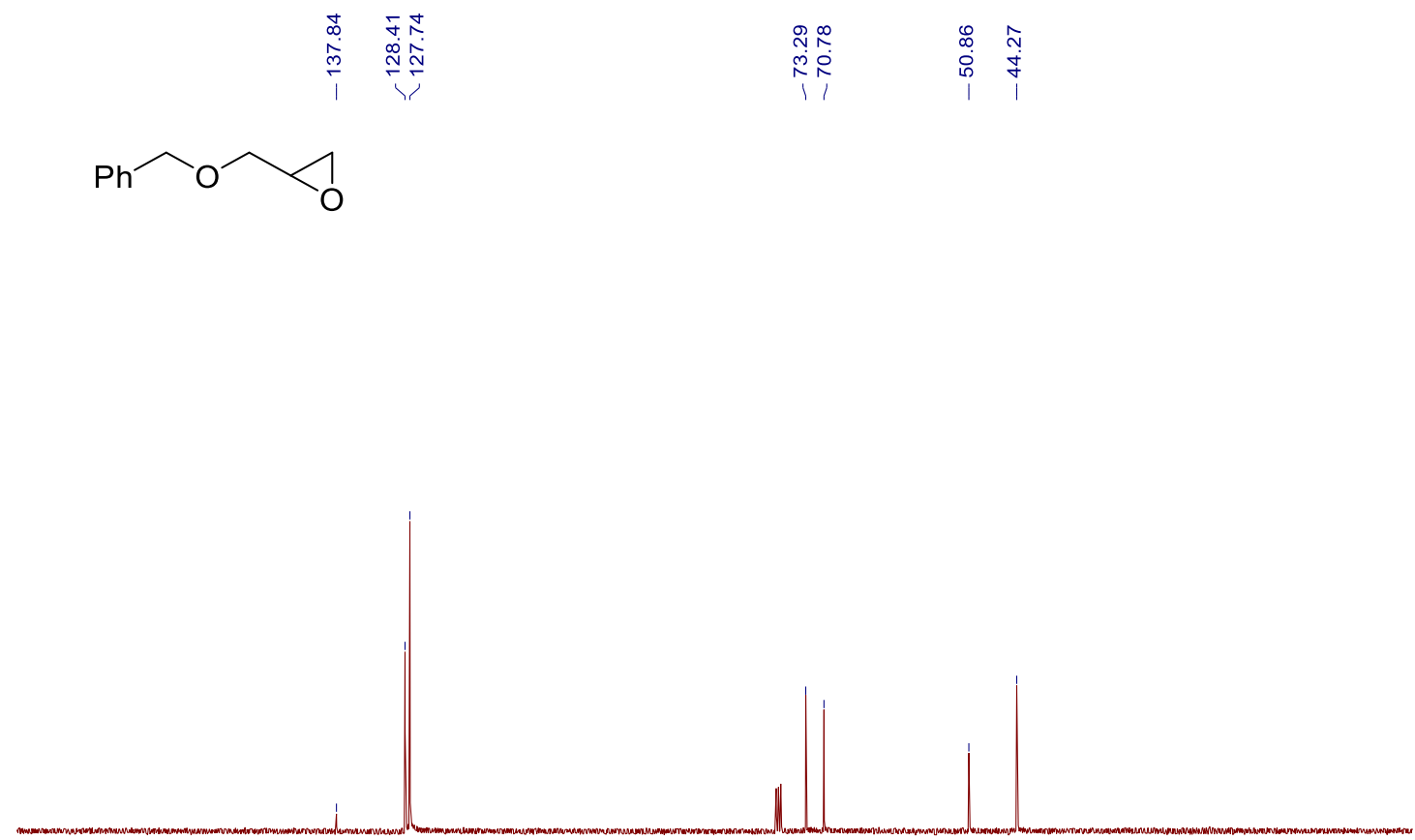

$\begin{array}{lllllllllllllllllllll}180 & 170 & 160 & 150 & 140 & 130 & 120 & 110 & 100 & \begin{array}{c}90 \\ \mathrm{f} 1(\mathrm{ppm})\end{array} & 70 & 60 & 50 & 40 & 30 & 20 & 10 & 0 & -\end{array}$

Phenoxyacetyl-2,3-epoxipropyl ester (2f)

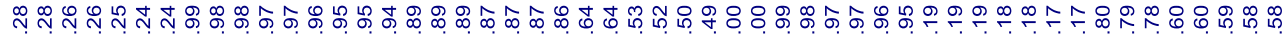
ヘ<smiles>O=C(COc1ccccc1)OCC1CO1</smiles>

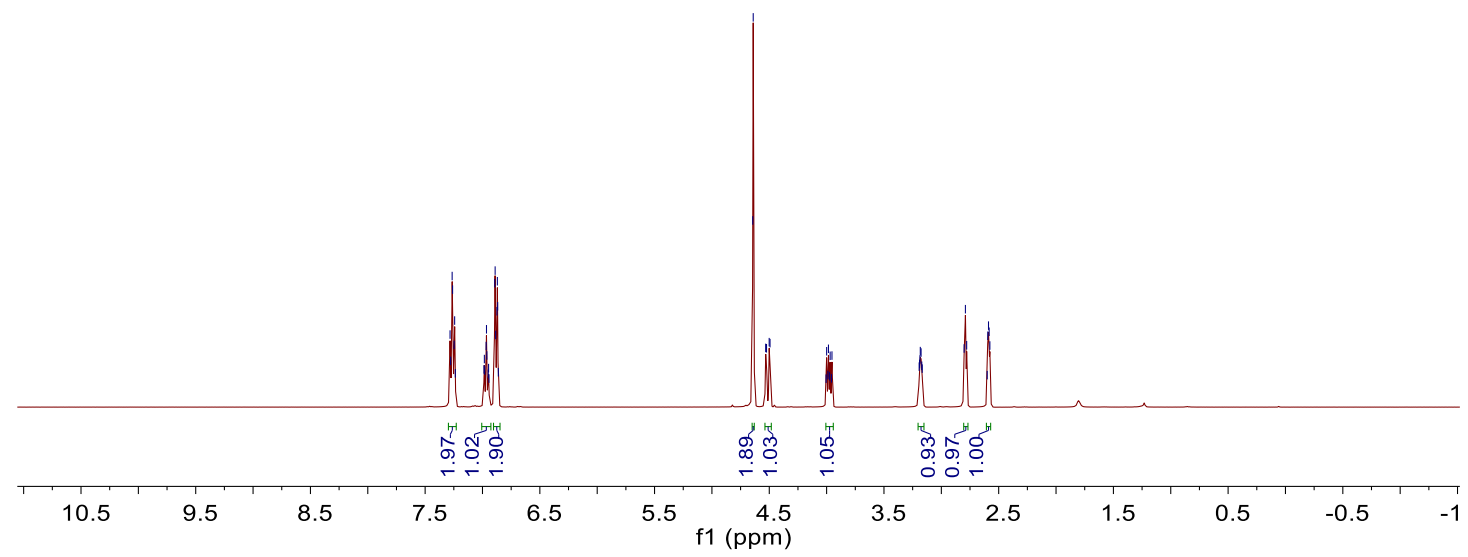




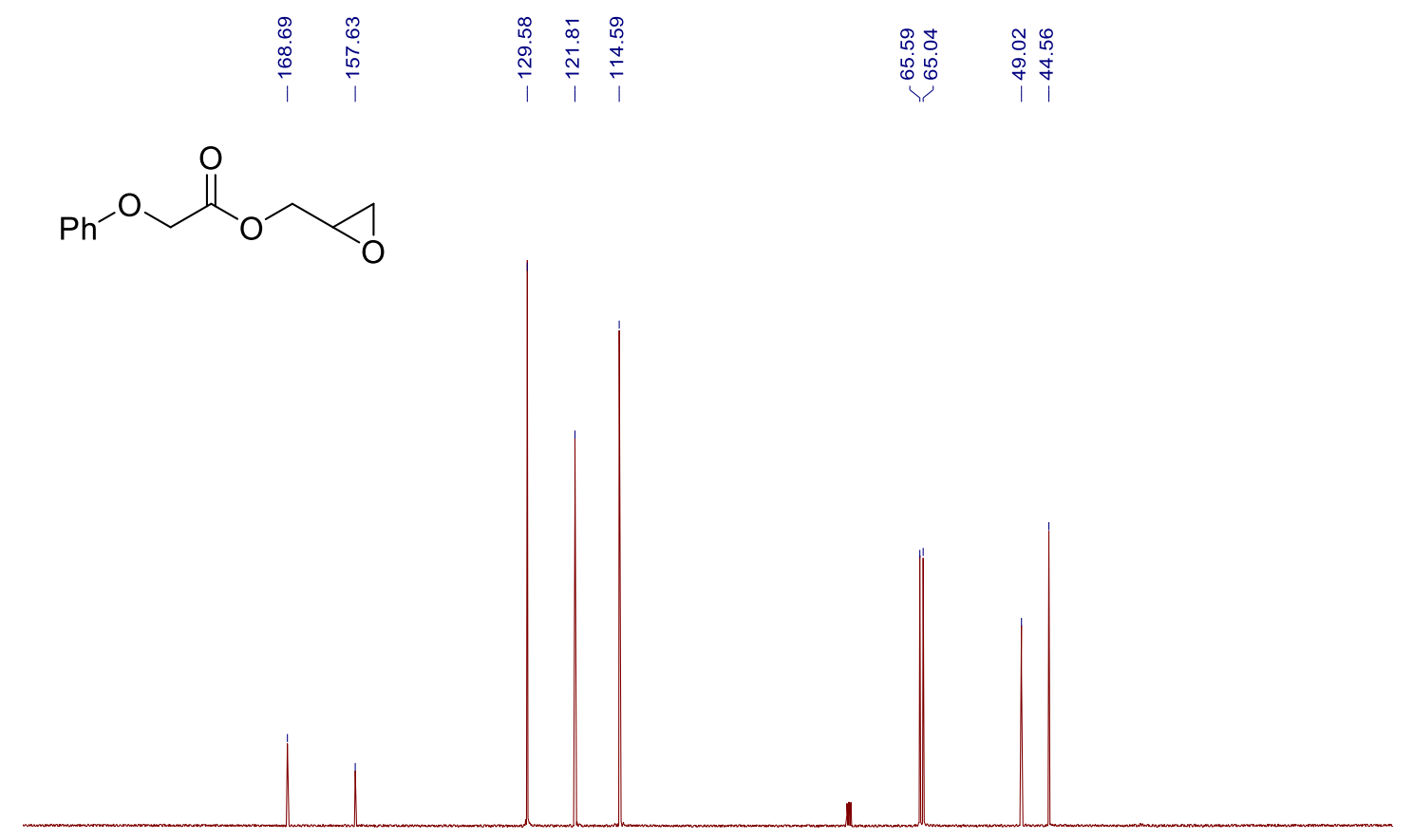

$\begin{array}{llllllllllllllllllllllll}210 & 200 & 190 & 180 & 170 & 160 & 150 & 140 & 130 & 120 & \begin{array}{c}110 \\ \mathrm{f} 1(\mathrm{ppm})\end{array} & \begin{array}{ll}100 \\ (\mathrm{ppm}\end{array} & 80 & 70 & 60 & 50 & 40 & 30 & 20 & 10 & 0 & -1\end{array}$

2-(Oxiran-2-ylmethyl)phenol (2g)

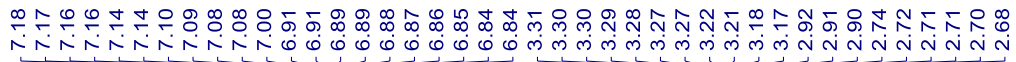<smiles>Oc1ccccc1CC1CO1</smiles>
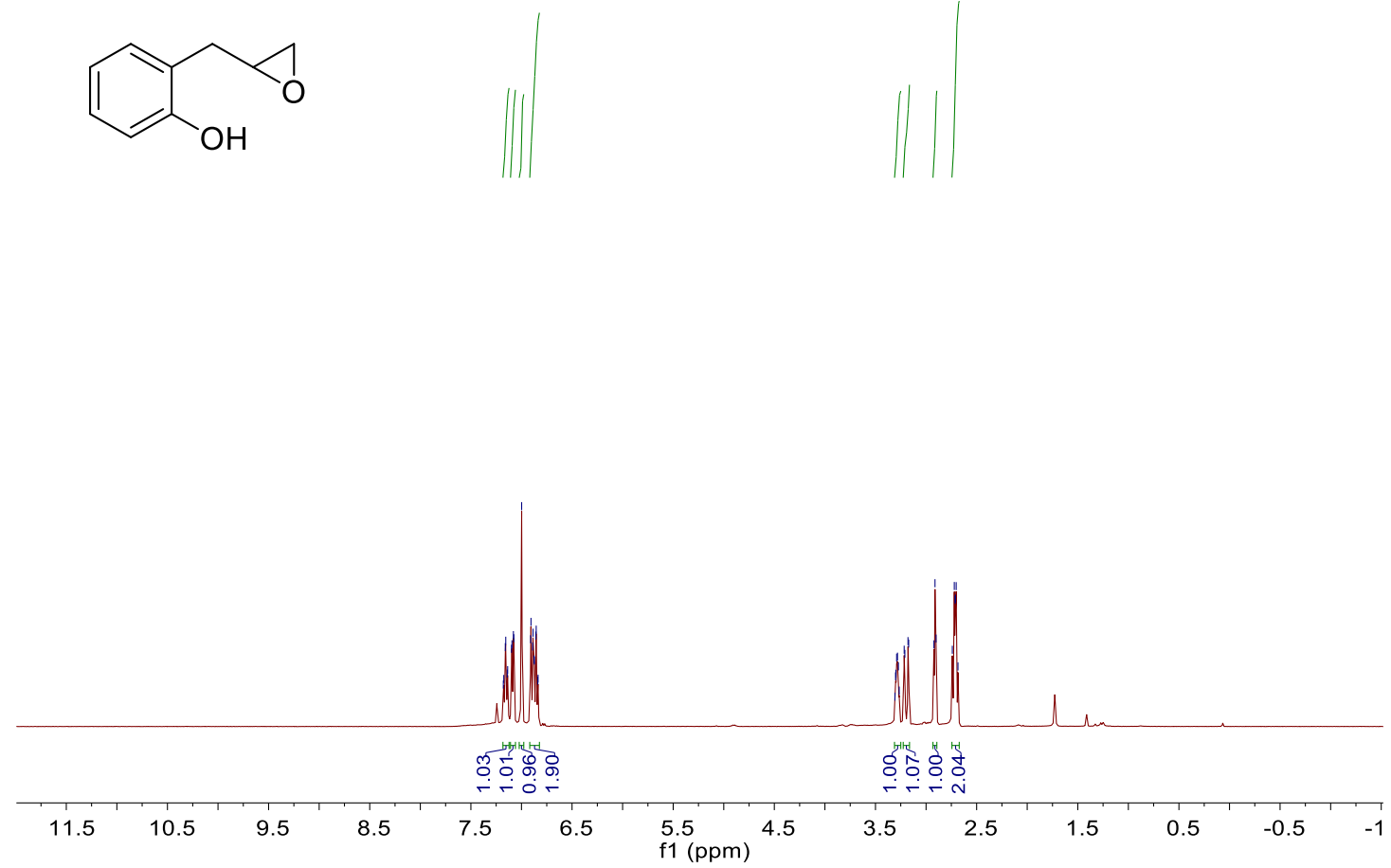
<smiles>Oc1ccccc1CC1CO1</smiles>

\section{옹수누요요}

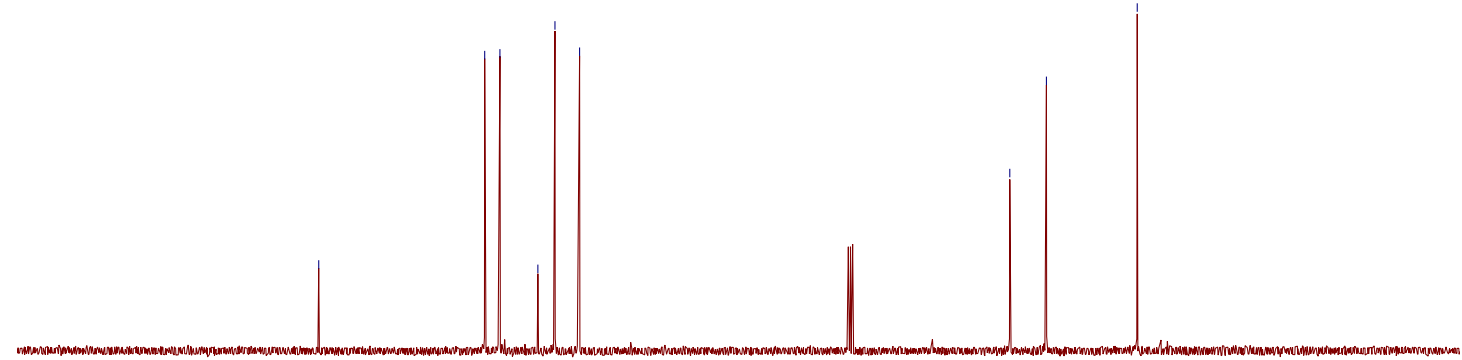

$\begin{array}{lllllllllllllllllllll}190 & 180 & 170 & 160 & 150 & 140 & 130 & 120 & 110 & \begin{array}{c}100 \\ \mathrm{f} 1(\mathrm{ppm})\end{array} & 80 & 70 & 60 & 50 & 40 & 30 & 20 & 10 & 0 & -10\end{array}$

\section{2,4-Methano-2H-indeno[1,2-b:5,6-b']bisoxirene (2h)}

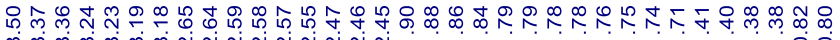

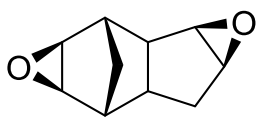
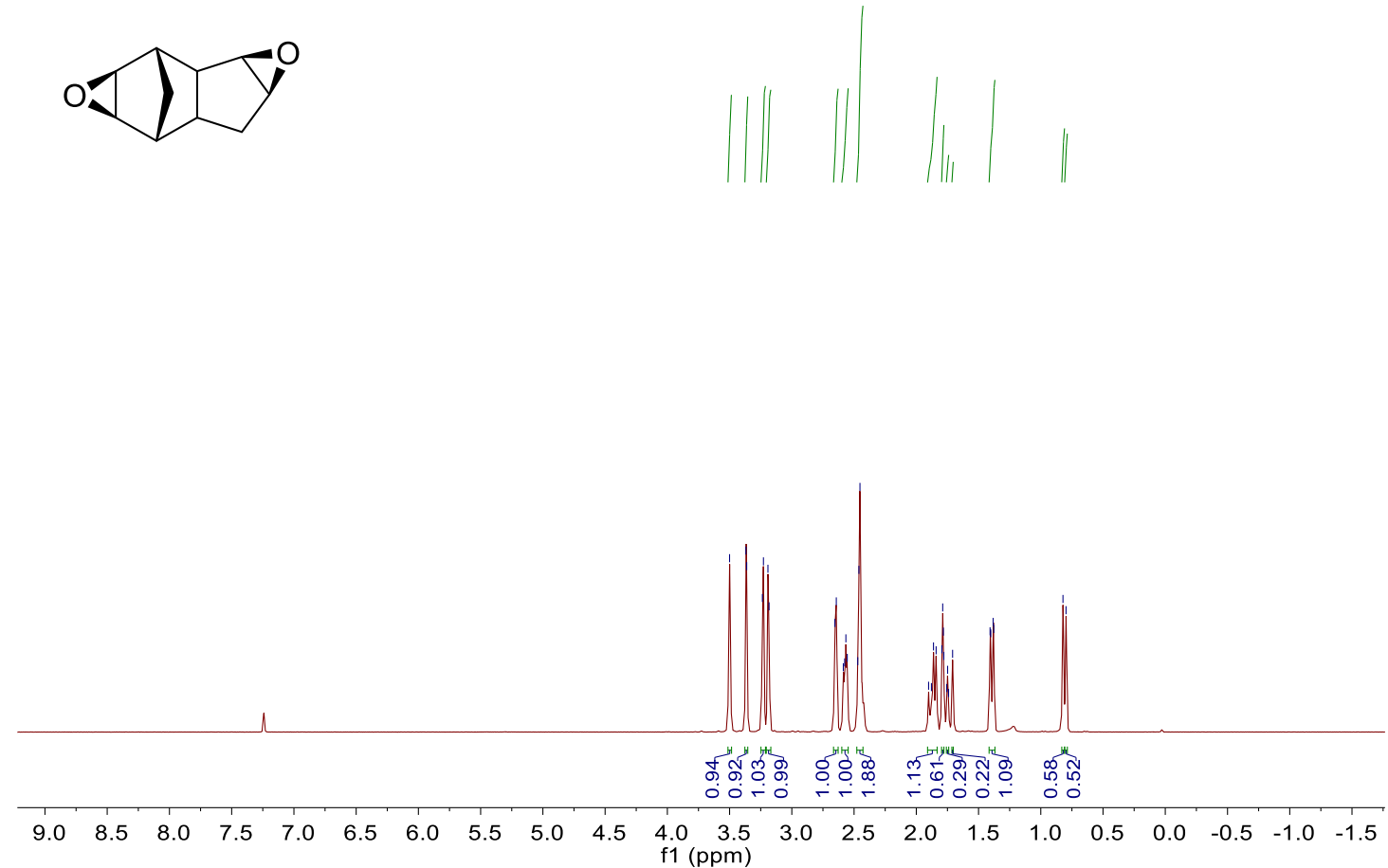


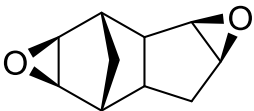
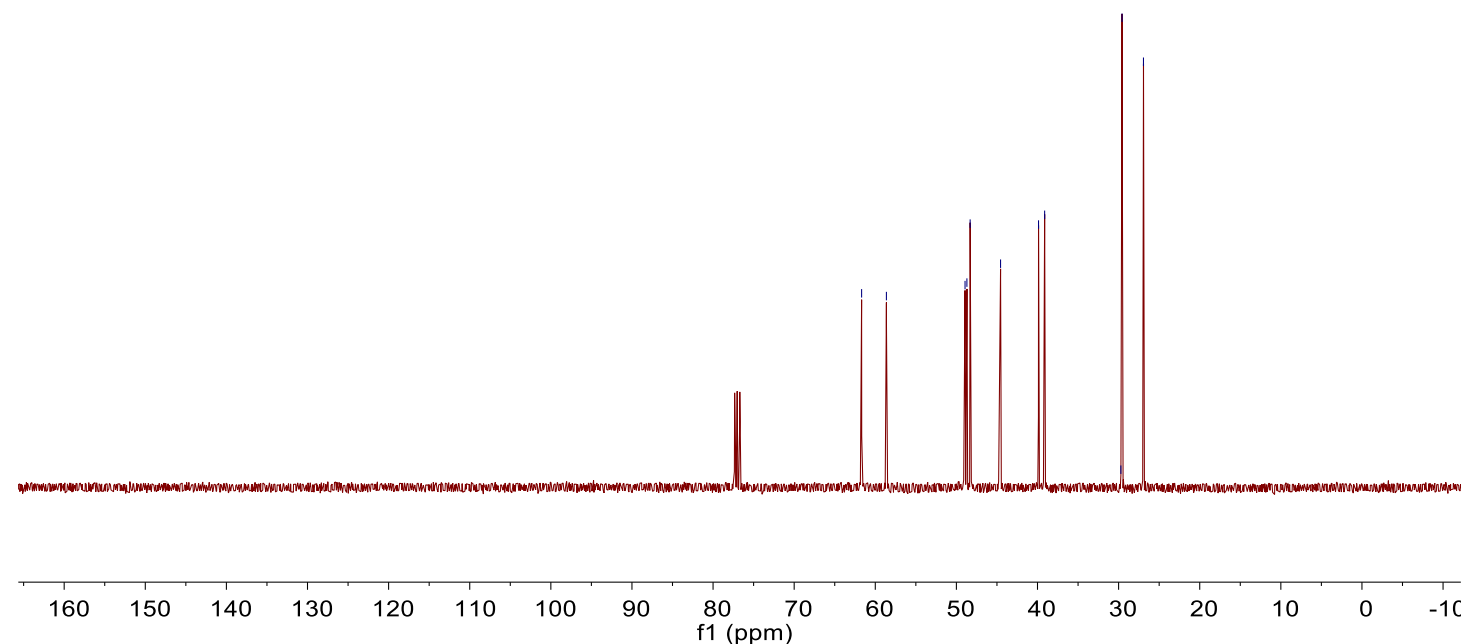

1,2-Epoxy-4-(2-oxiranyl)cyclohexane (2i)

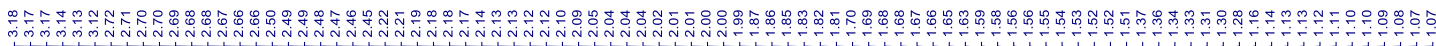<smiles>C1CC2OC2CC1C1CO1</smiles>
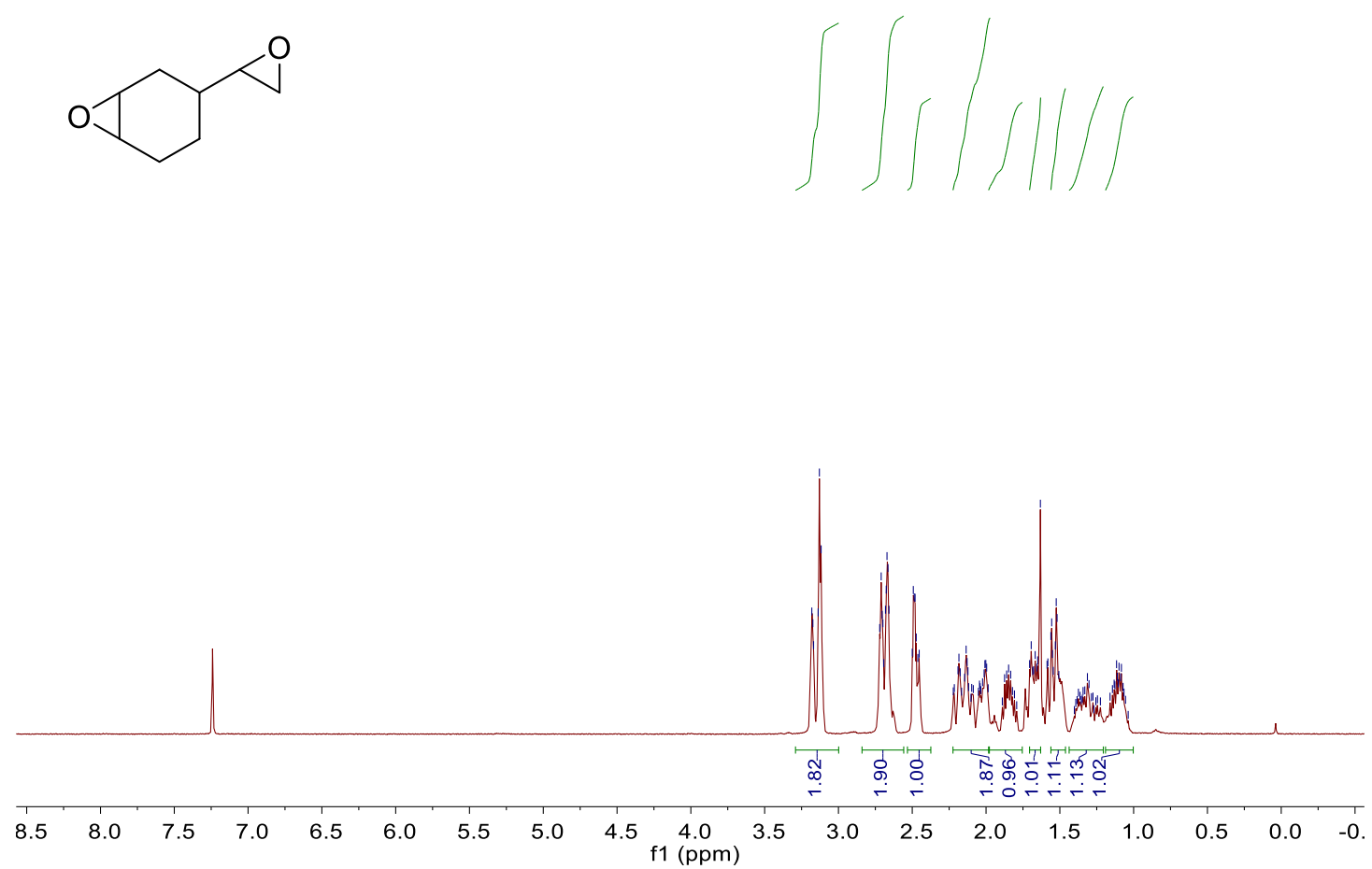
<smiles>C1CC2OC2CC1C1CO1</smiles>

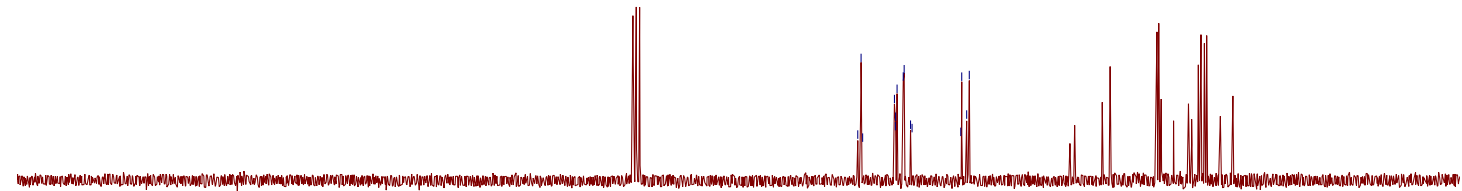

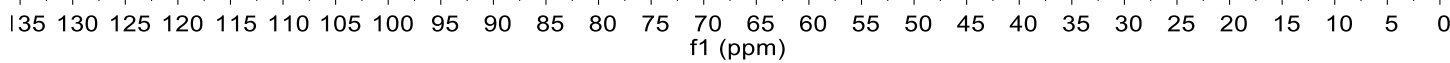

2-(4-Bromophenyl)oxirane (2j)

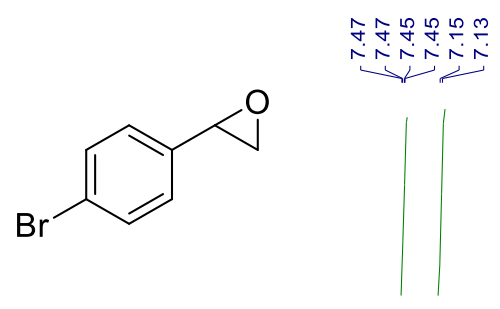

$\underset{\infty}{\infty} \infty \infty_{\infty}^{\infty} \infty$

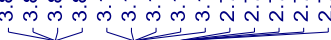
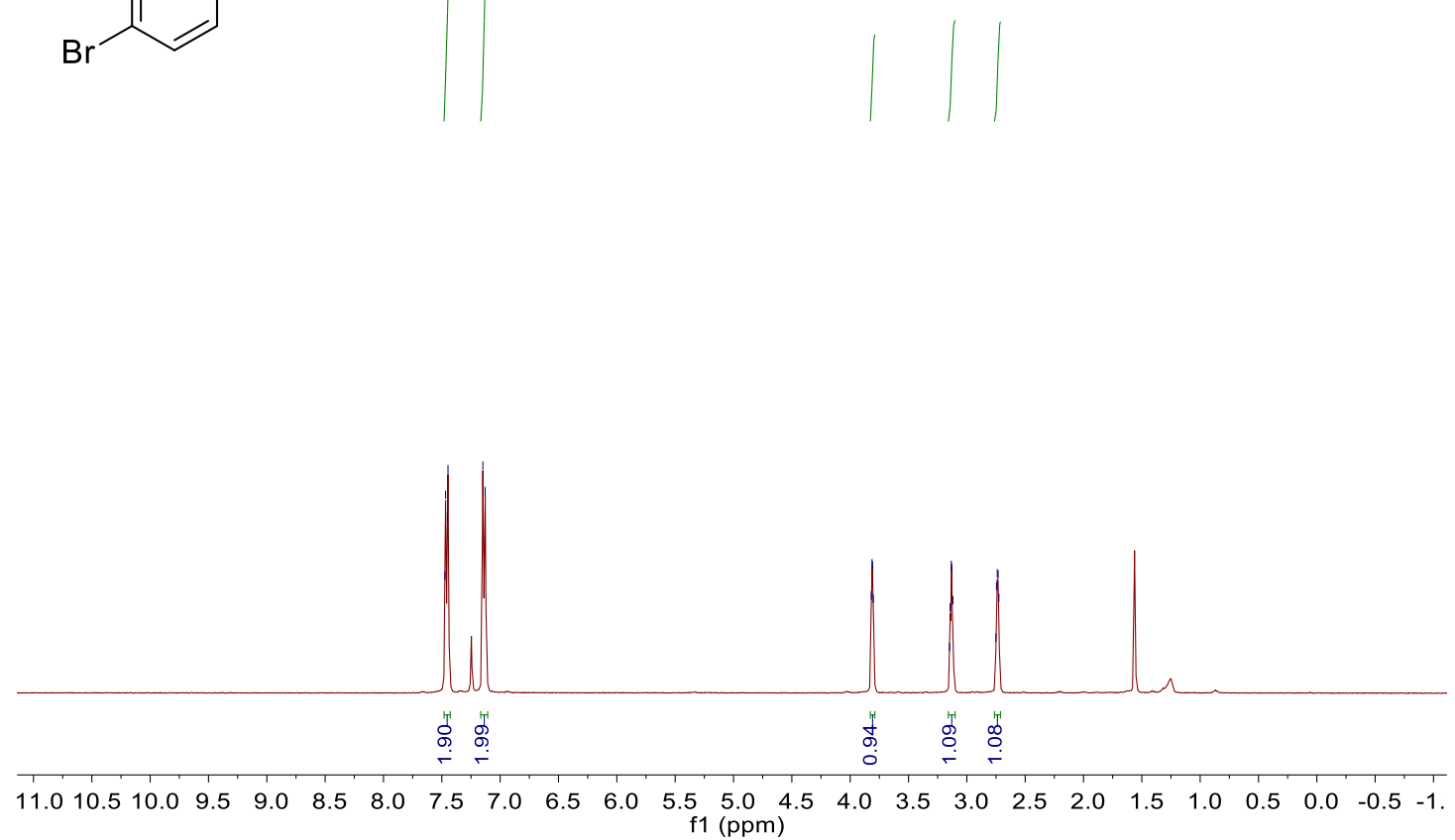


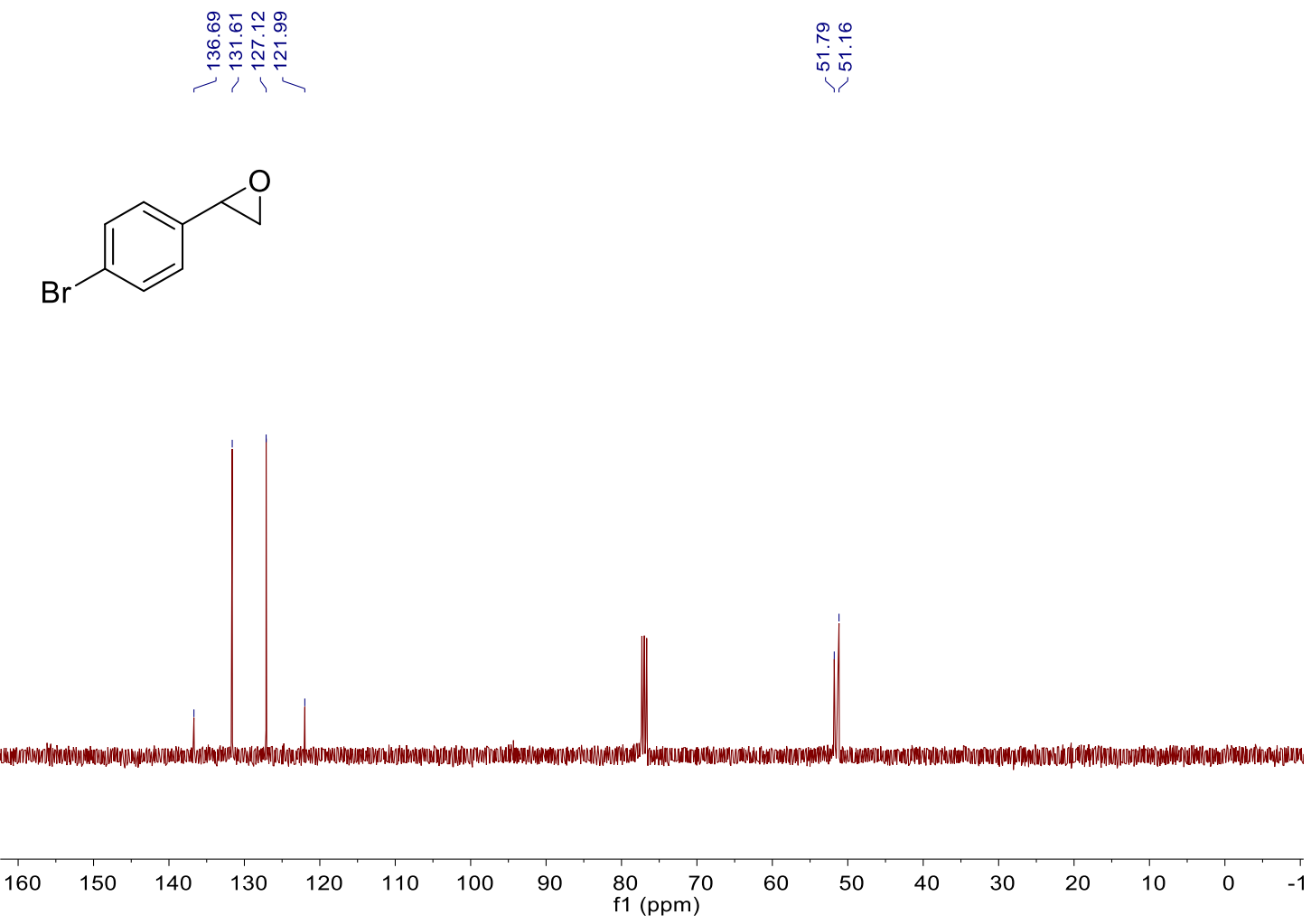

2-(4-Chlorophenyl)oxirane (2k)
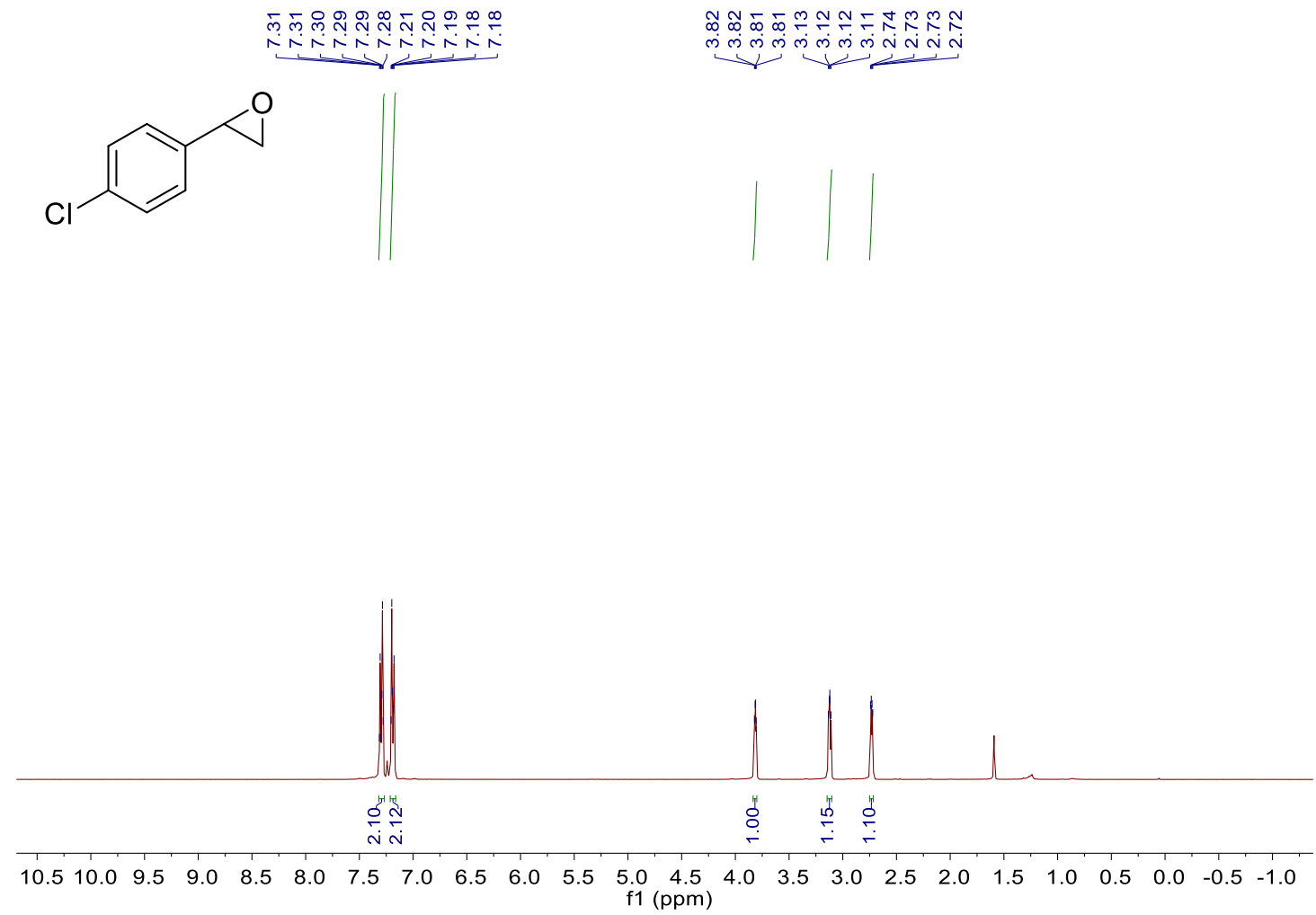


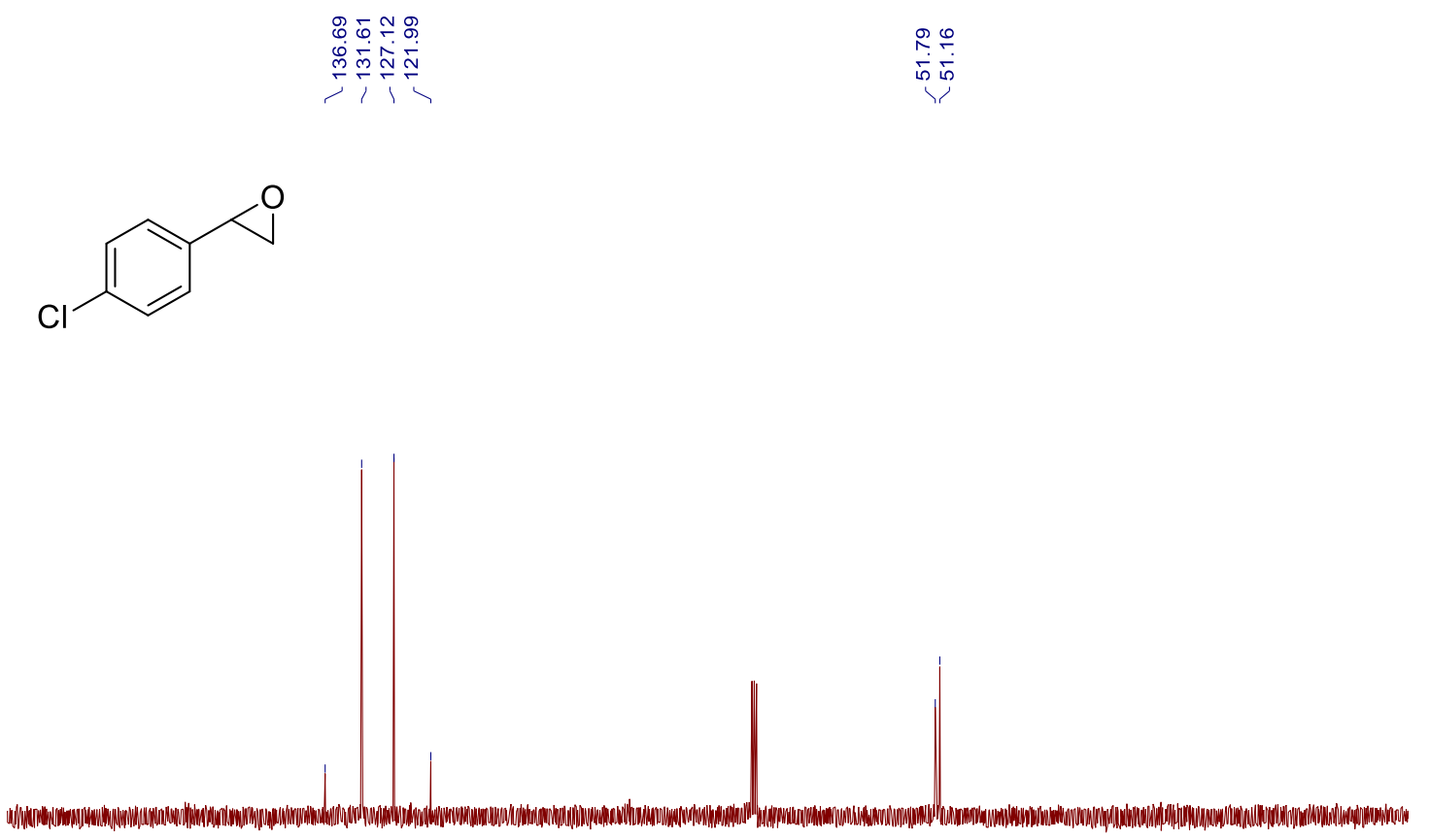

$\begin{array}{lllllllllllllllllllll}80 & 170 & 160 & 150 & 140 & 130 & 120 & 110 & 100 & 90 & 80 & 70 & 60 & 50 & 40 & 30 & 20 & 10 & 0 & -10\end{array}$

4-Methoxycarbonylstyrene oxide (2I)
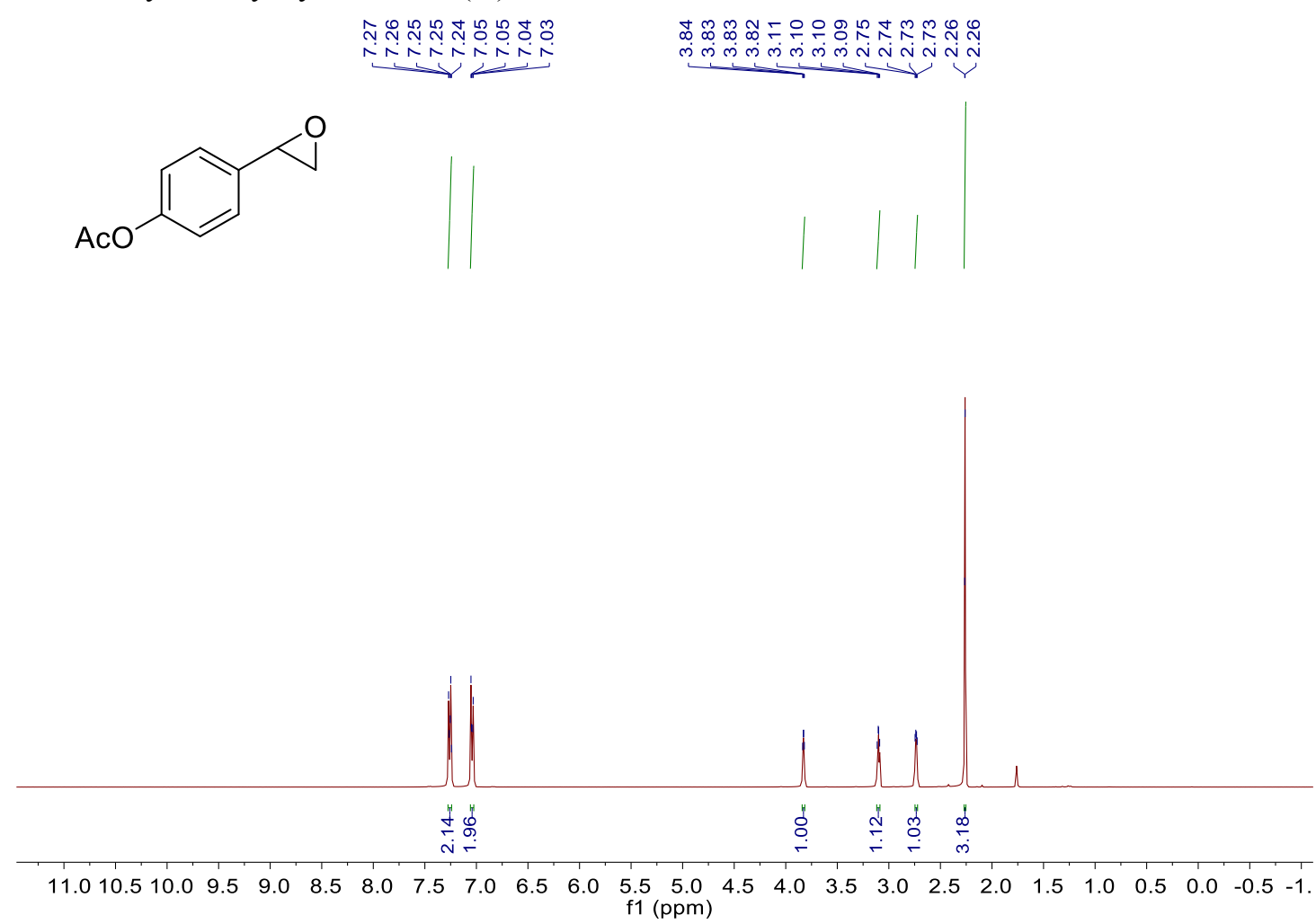


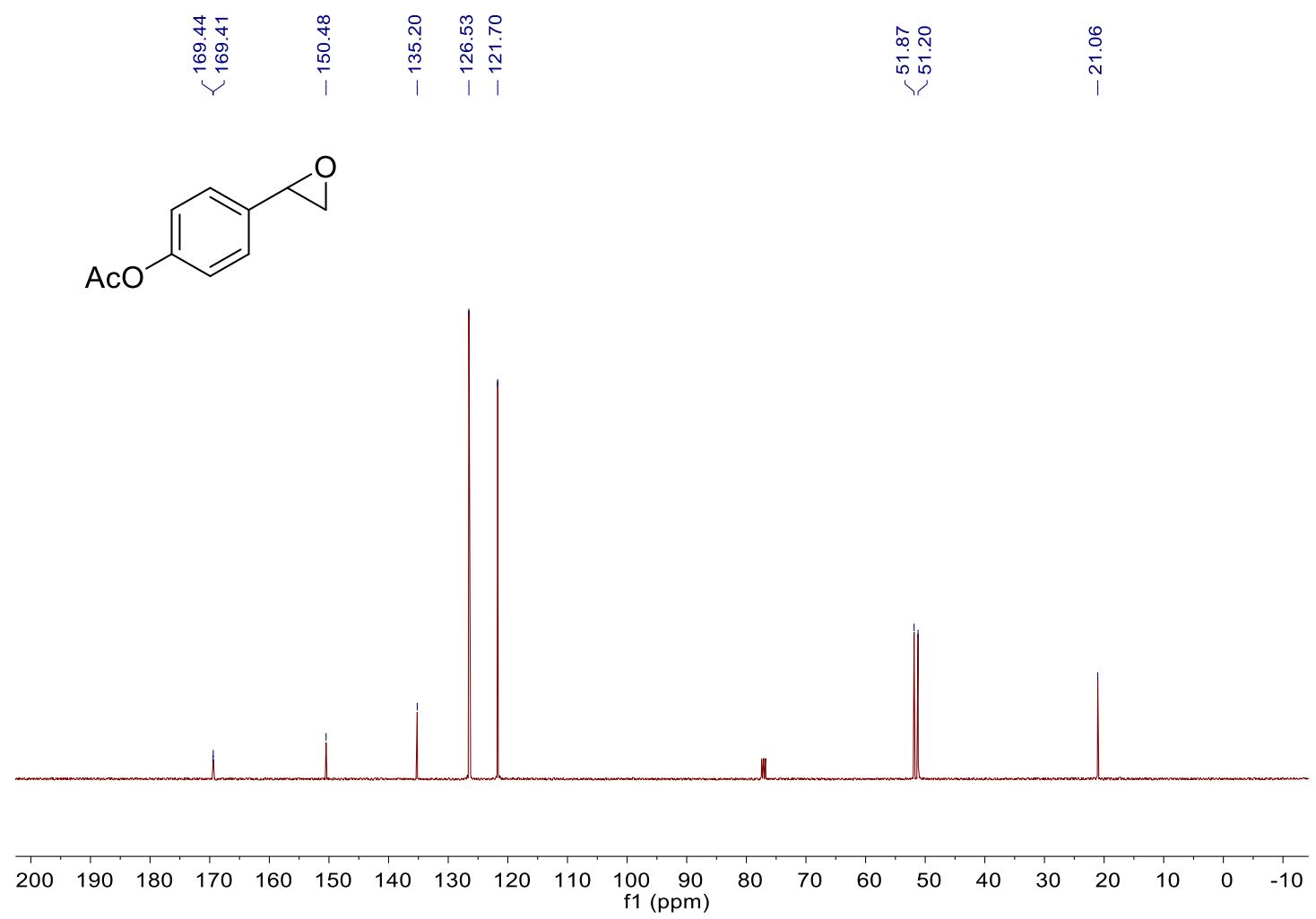

2-(4-Nitrophenyl)oxirane (2m)
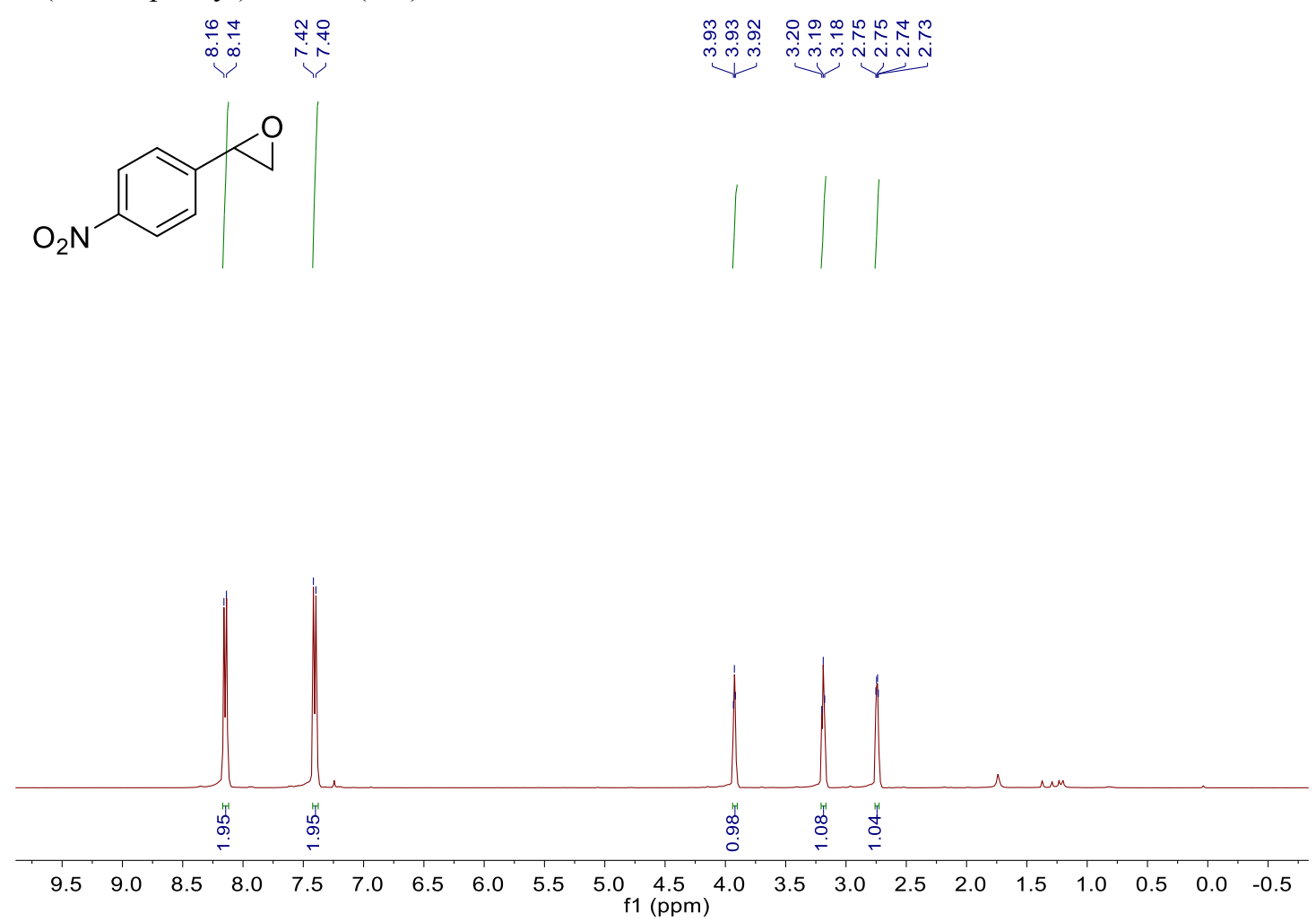


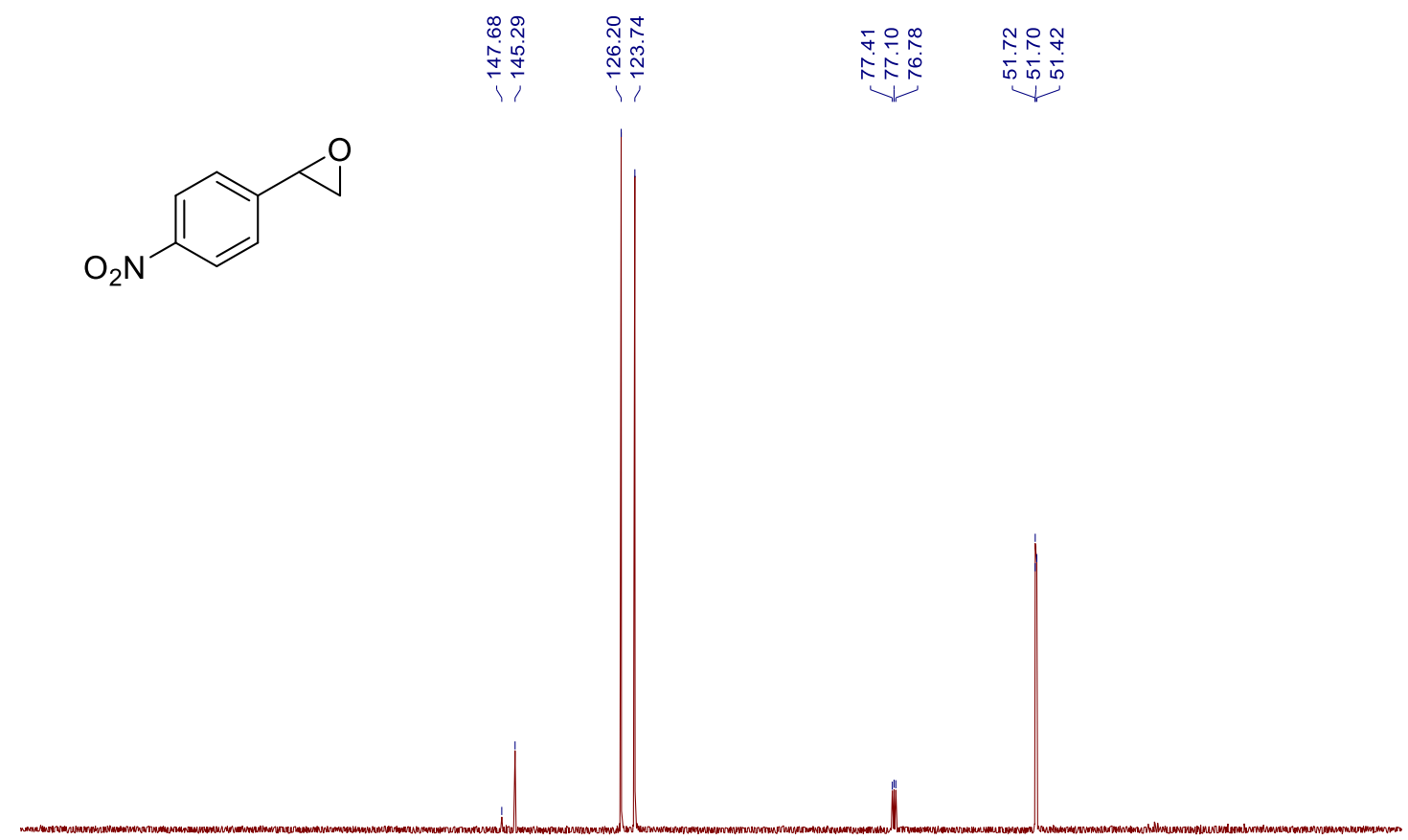

$\begin{array}{lllllllllllllllllllllllll}230 & 220 & 210 & 200 & 190 & 180 & 170 & 160 & 150 & 140 & 130 & 120 & 110 & 100 & 90 & 80 & 70 & 60 & 50 & 40 & 30 & 20 & 10 & 0 & -10\end{array}$ f1 (ppm)

trans-Stilbene oxide (2n)

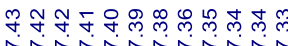<smiles></smiles>

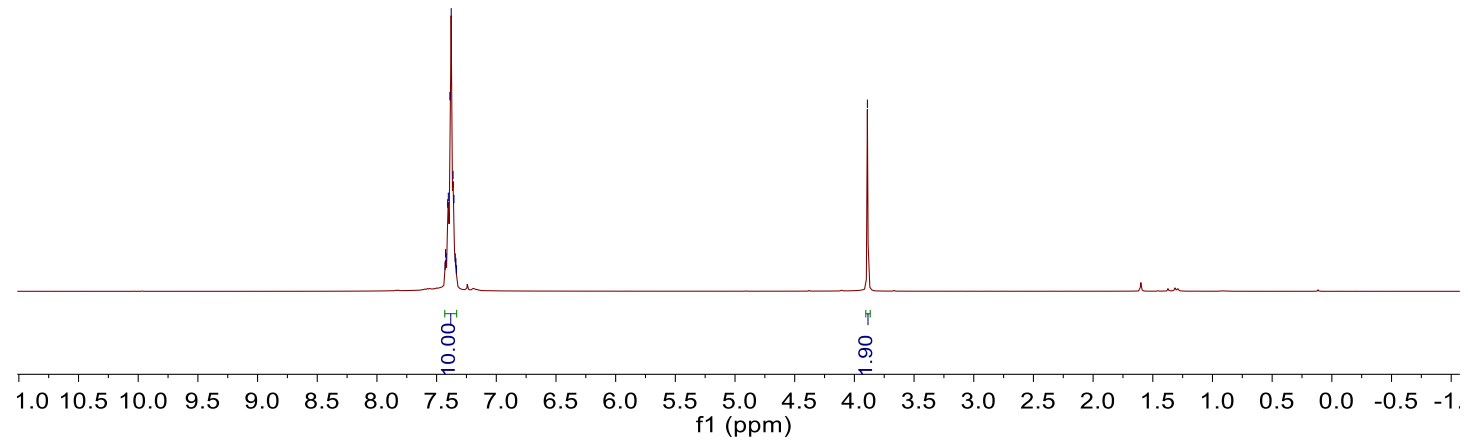


$\mathrm{Ph} \stackrel{\mathrm{O}}{\mathrm{Ph}}$

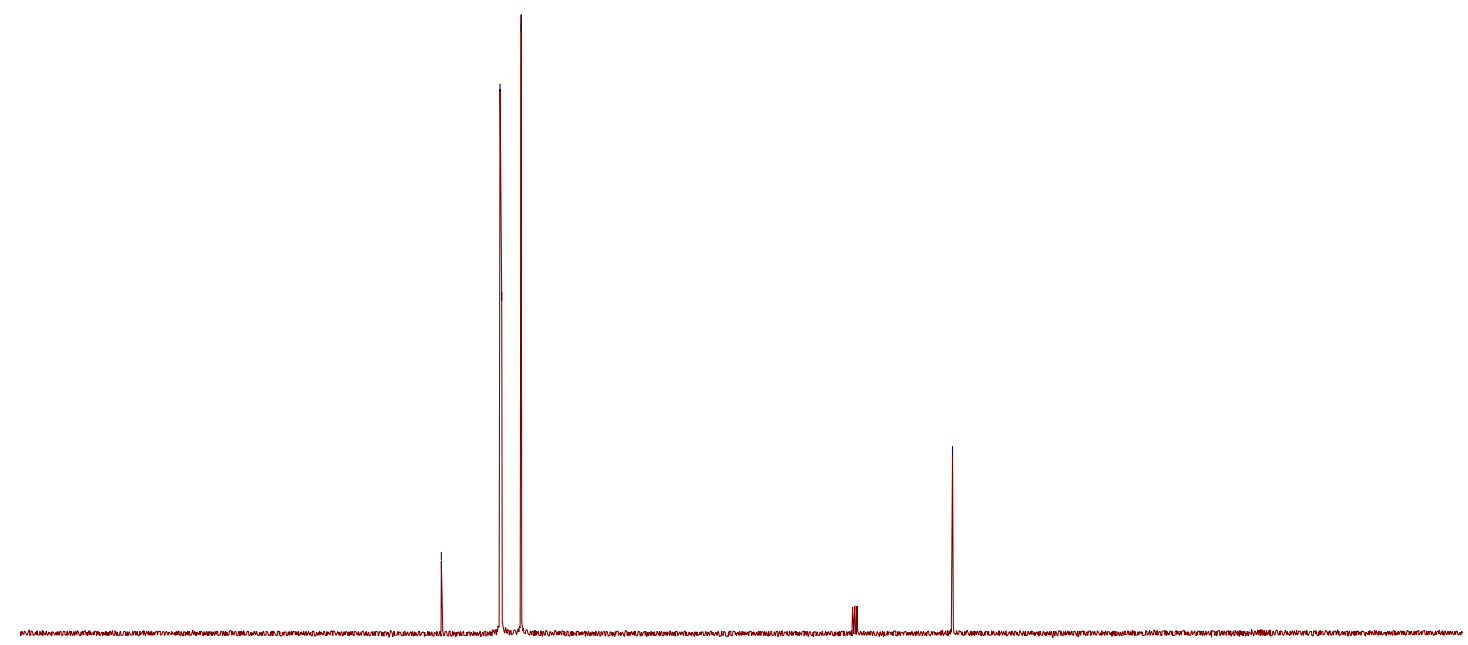

$\begin{array}{llllllllllllllllllll}190 & 180 & 170 & 160 & 150 & 140 & 130 & 120 & 110 & \begin{array}{c}100 \\ \mathrm{f} 1(\mathrm{ppm})\end{array} & 80 & 70 & 60 & 50 & 40 & 30 & 20 & 10 & 0 & -1\end{array}$

cis-Stilbene oxide (2o)

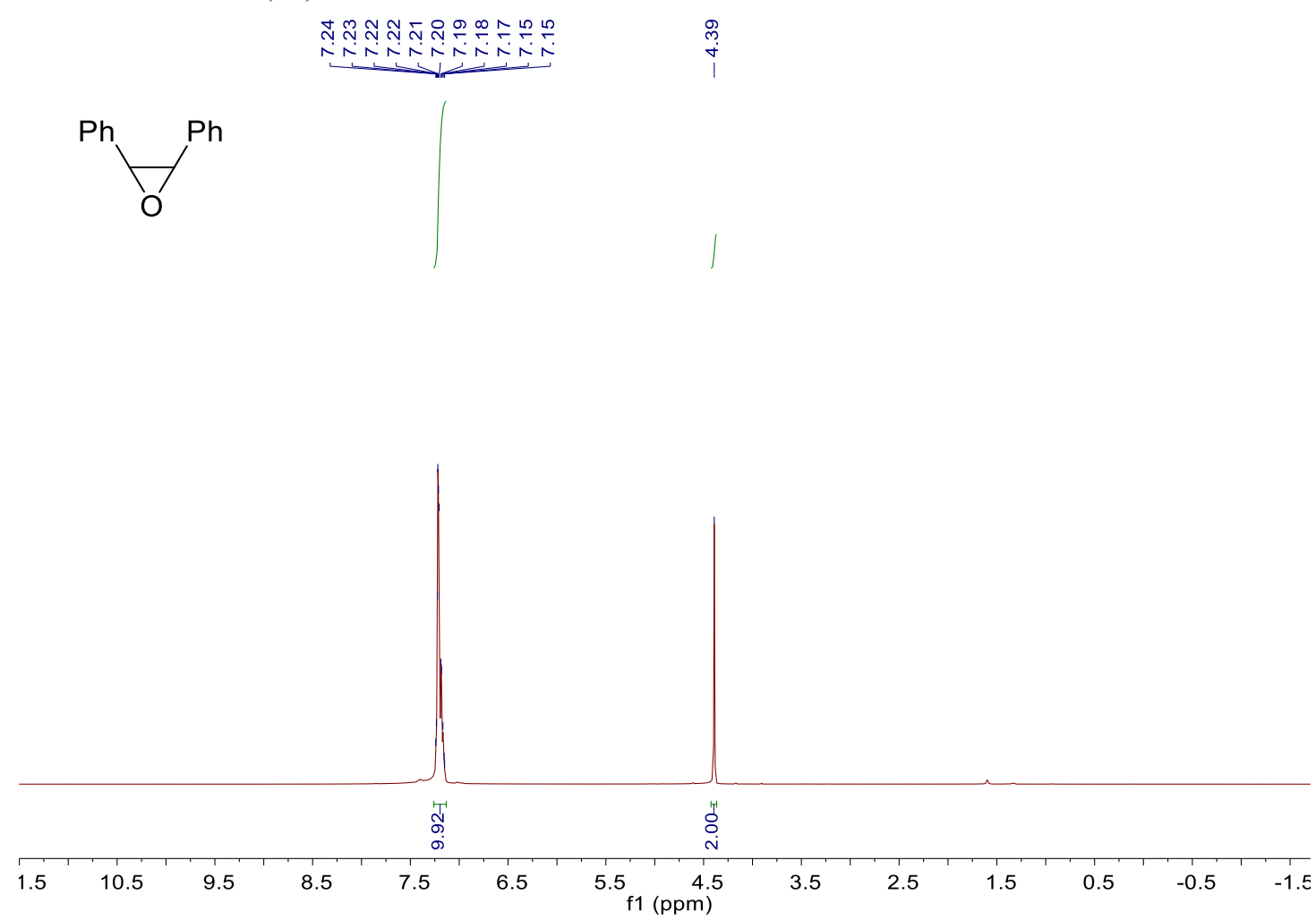




$$
\text { \& }
$$<smiles>Pc1ccccc1</smiles>

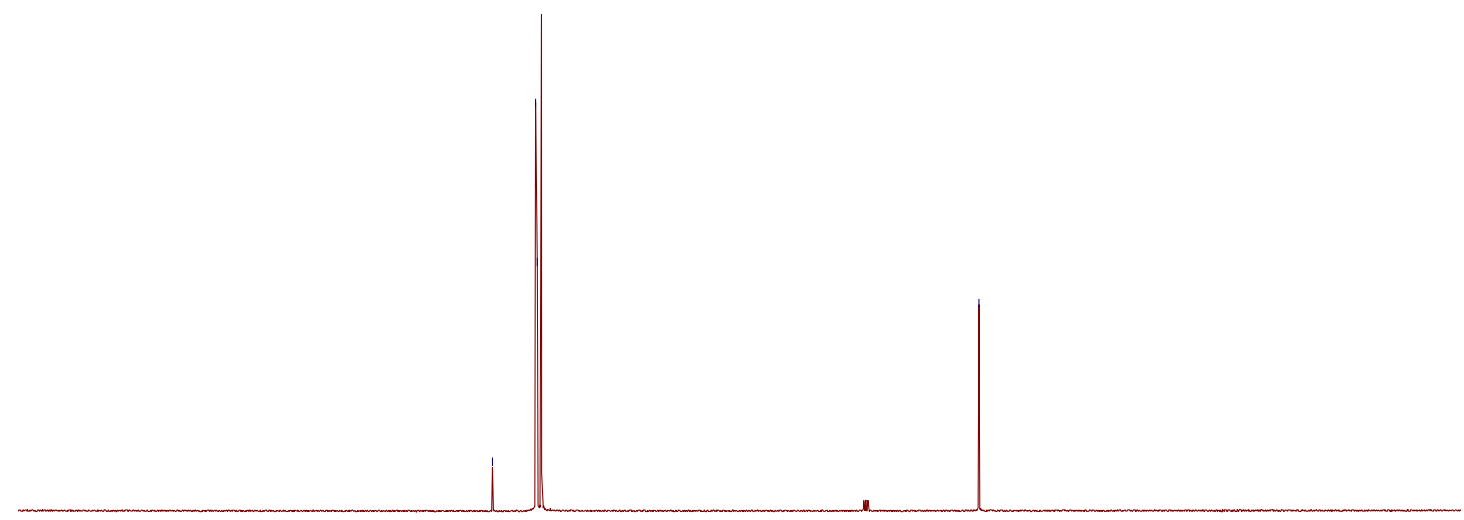

$\begin{array}{llllllllllllllllllllll}200 & 190 & 180 & 170 & 160 & 150 & 140 & 130 & 120 & 110 & 100 & 90 & 80 & 70 & 60 & 50 & 40 & 30 & 20 & 10 & 0 & -10\end{array}$ f1 (ppm)

2,2,3,3-Tetraphenyloxirane (2p)

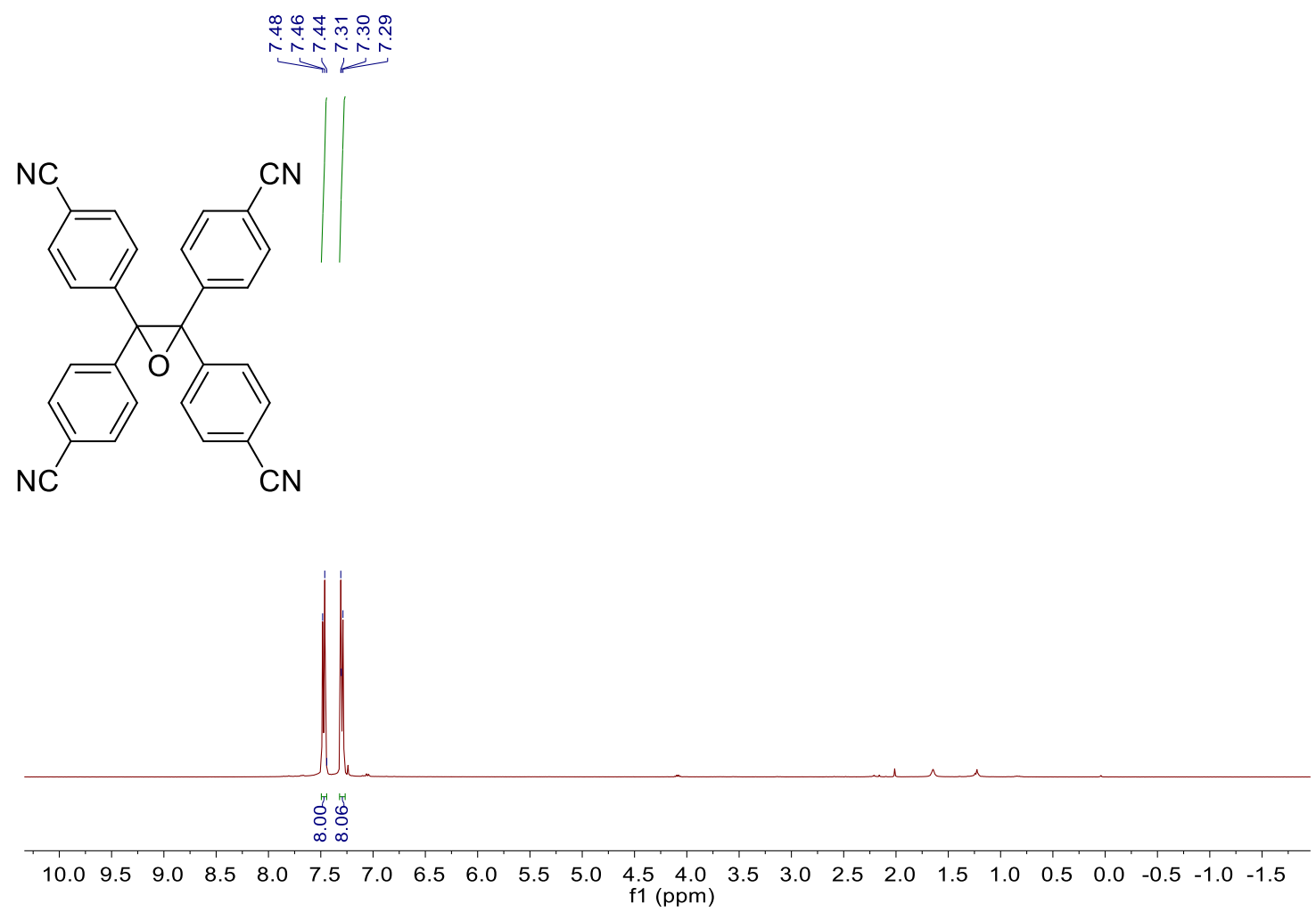




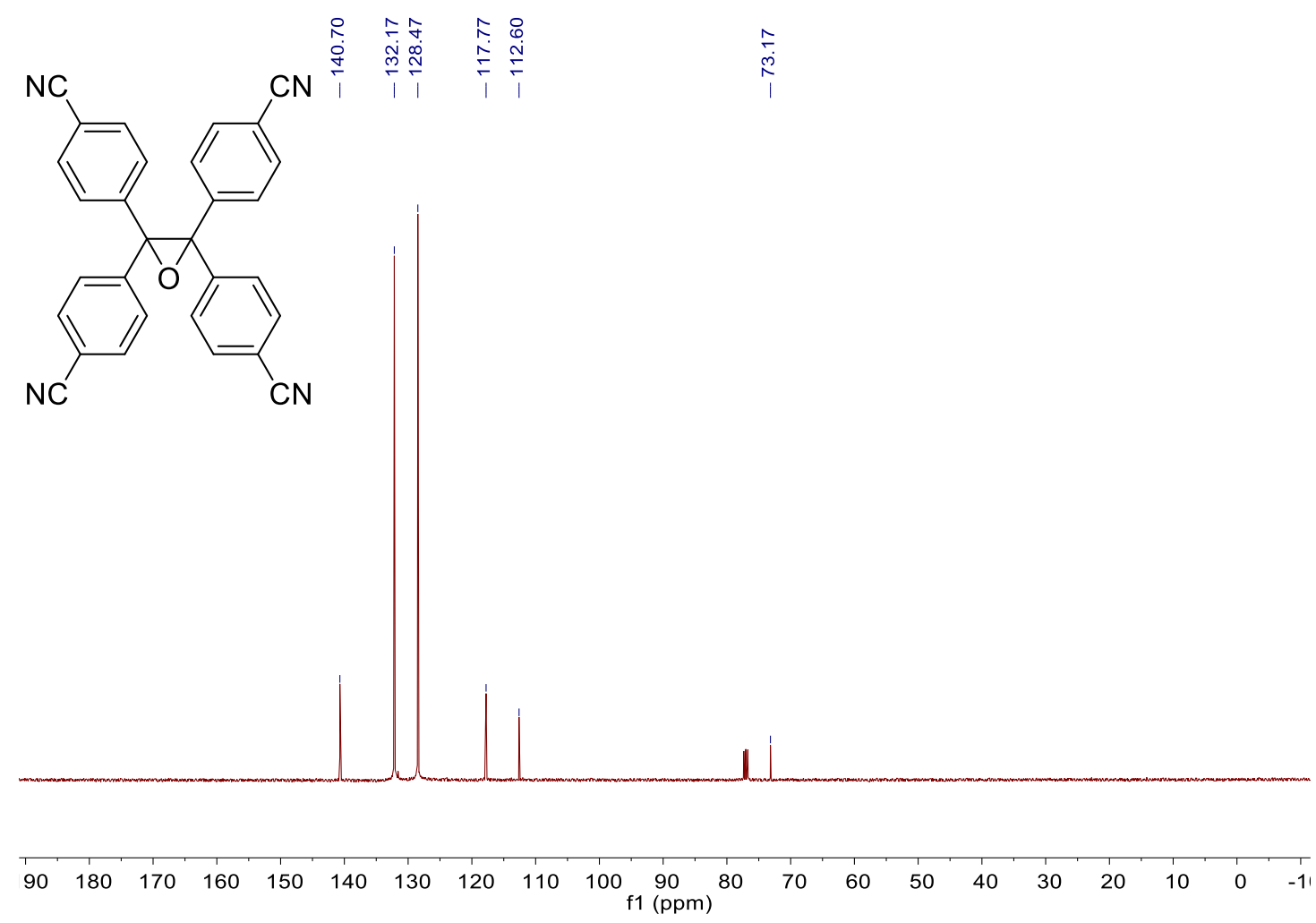

1,2-Epoxy propanoic acid benzyl ester (2q)
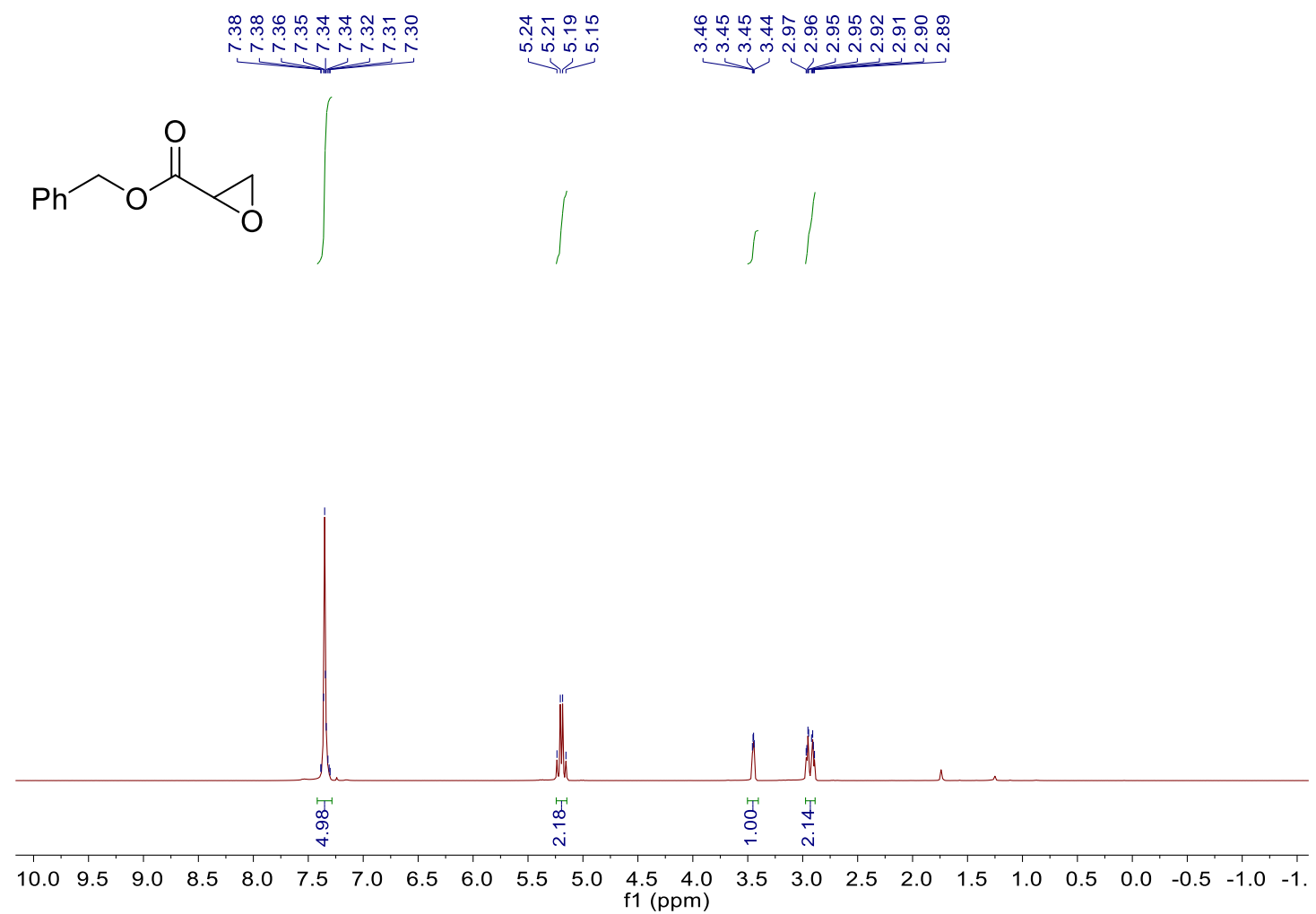


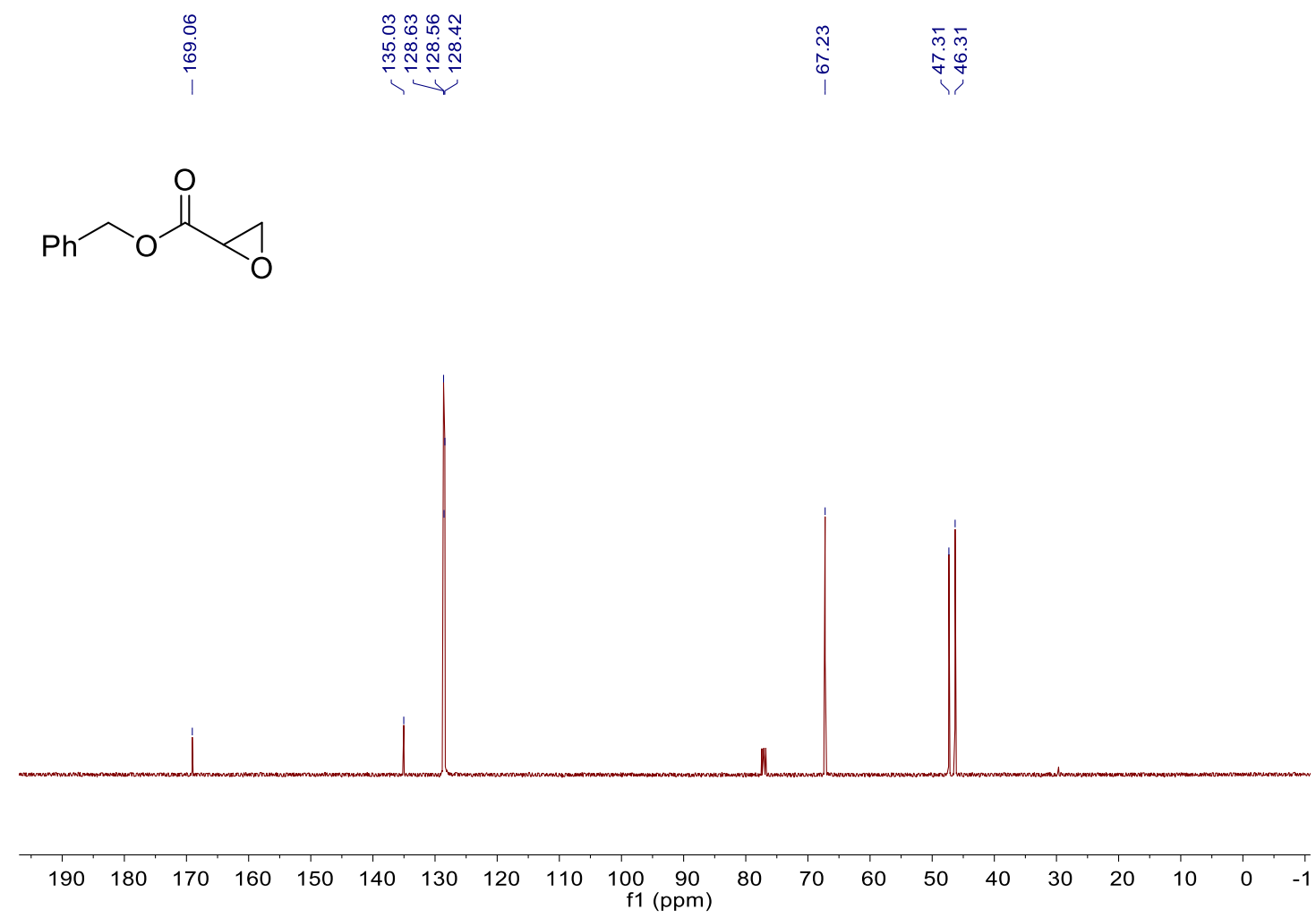

Phenyl(3-phenyl-2-oxiranyl)methanone (2r)

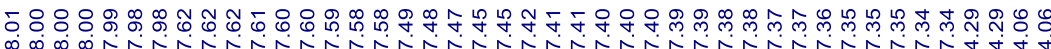

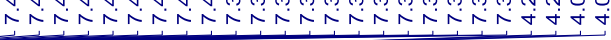

${ }_{\mathrm{Ph}}^{\mathrm{O}} \stackrel{\mathrm{N}}{\mathrm{Ph}}$

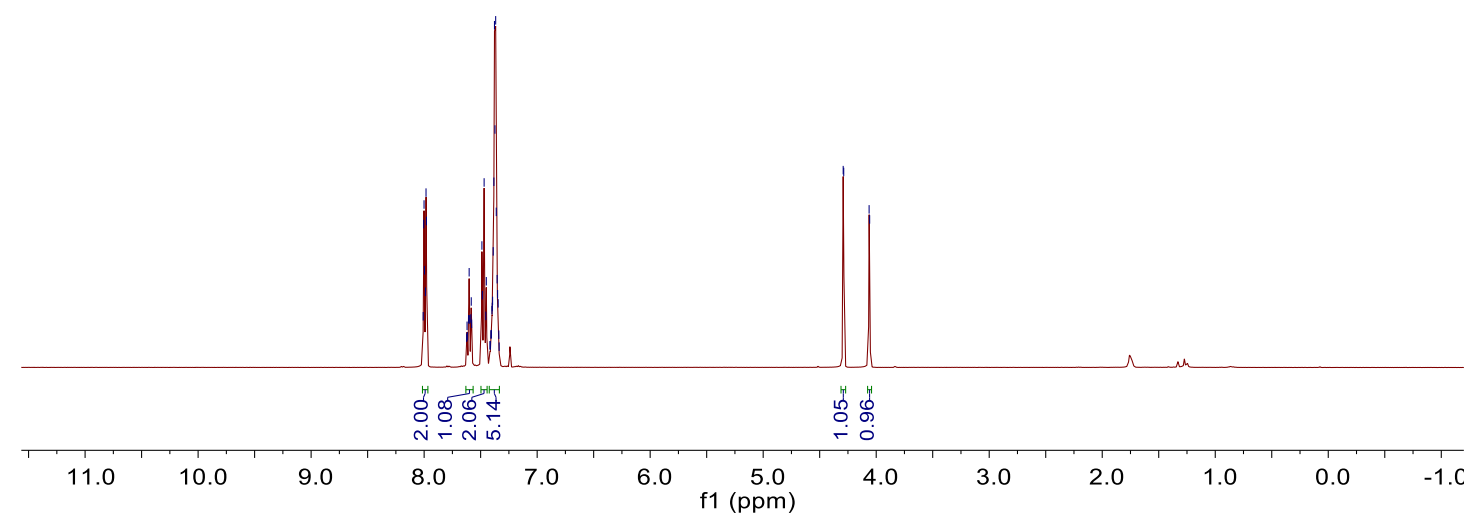


<smiles>O=C(c1ccccc1)C1OC1c1ccccc1</smiles>

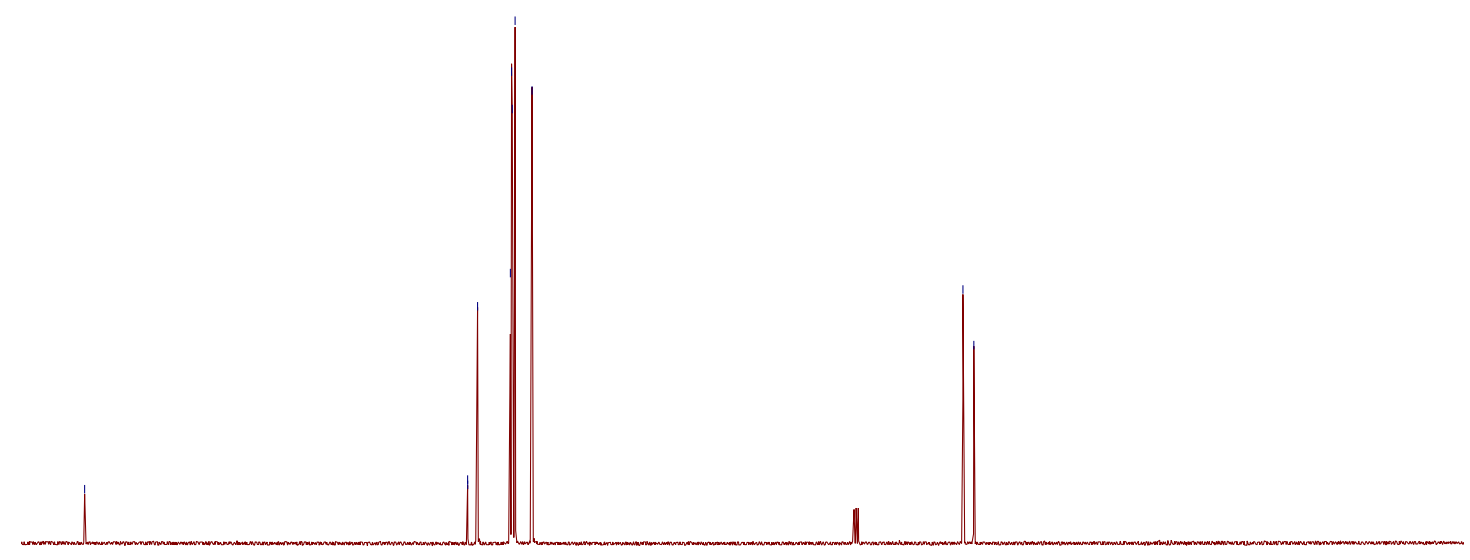

$\begin{array}{llllllllllllllllllllll}200 & 190 & 180 & 170 & 160 & 150 & 140 & 130 & 120 & 110 & \begin{array}{c}100 \\ \mathrm{f} 1(\mathrm{ppm})\end{array} & 80 & 70 & 60 & 50 & 40 & 30 & 20 & 10 & 0 & -10\end{array}$

1-Phenyl-2-methoxycarbonyloxirane (2s)
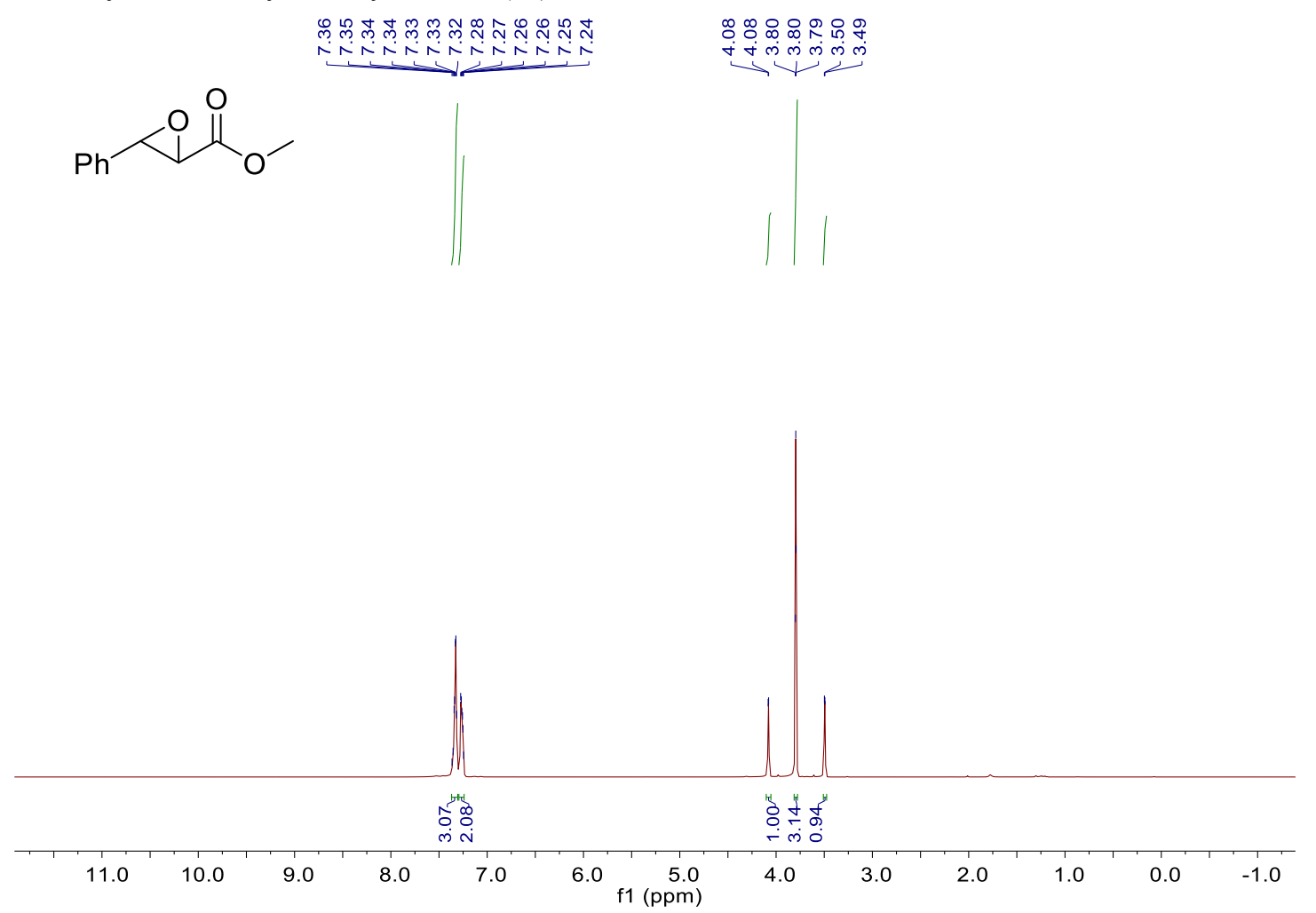


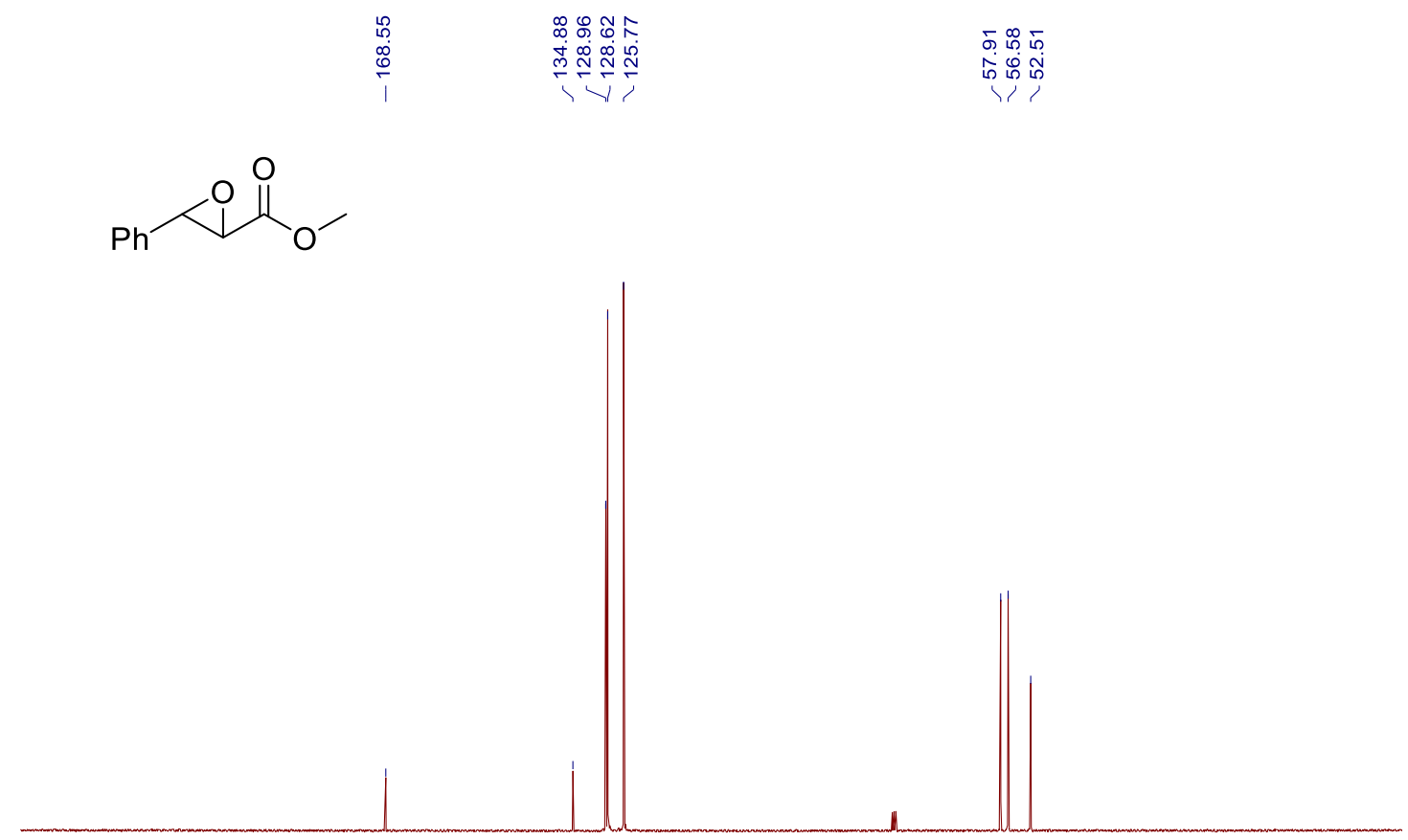

$\begin{array}{llllllllllllllllllllllllll}230 & 220 & 210 & 200 & 190 & 180 & 170 & 160 & 150 & 140 & 130 & 120 & 110 & 100 & 90 & 80 & 70 & 60 & 50 & 40 & 30 & 20 & 10 & 0 & -10\end{array}$ f1 (ppm)

Diethyl 2,3-oxiranedicarboxylate (2t)
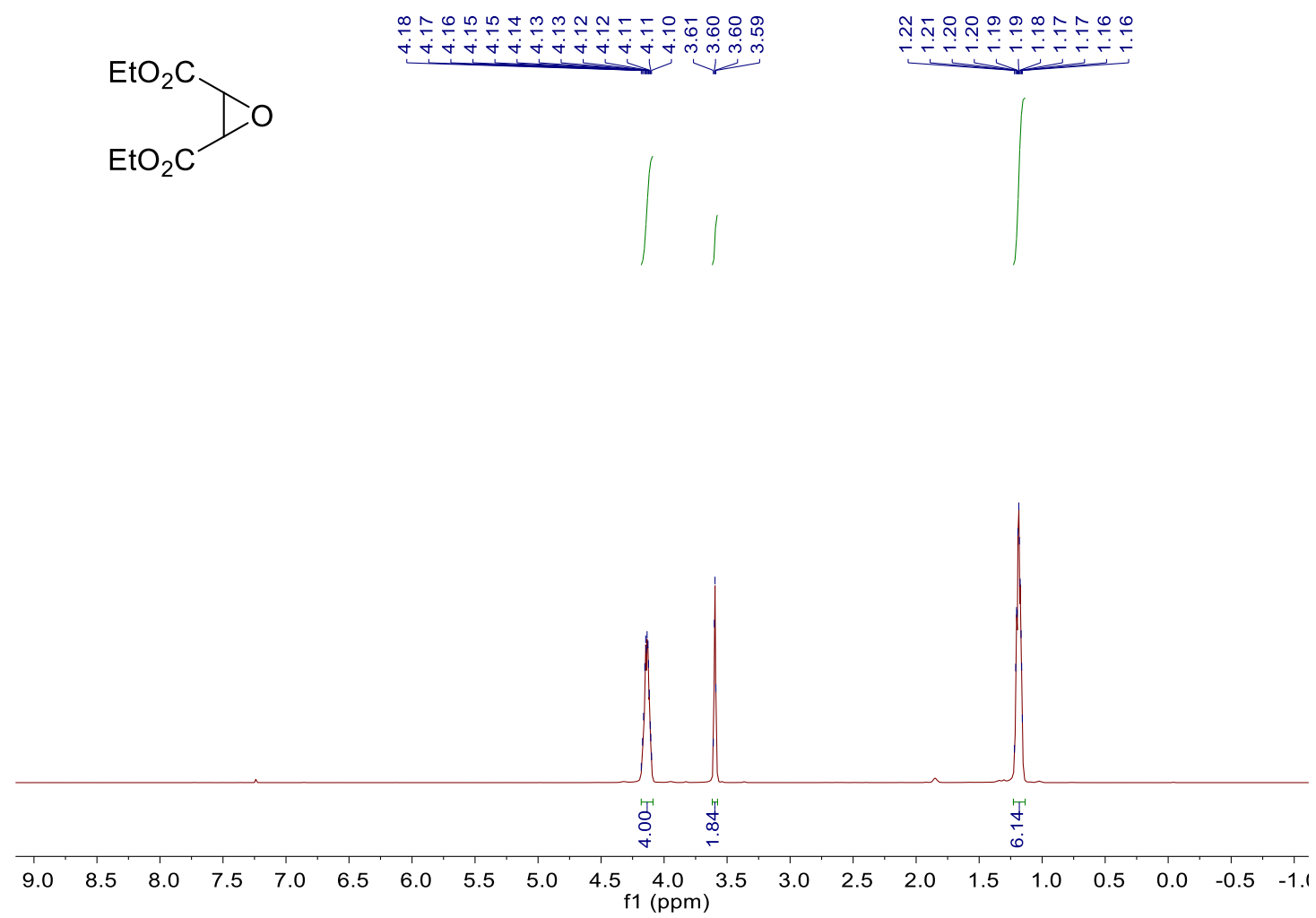
<smiles>CCOCC1OC1COCC</smiles>

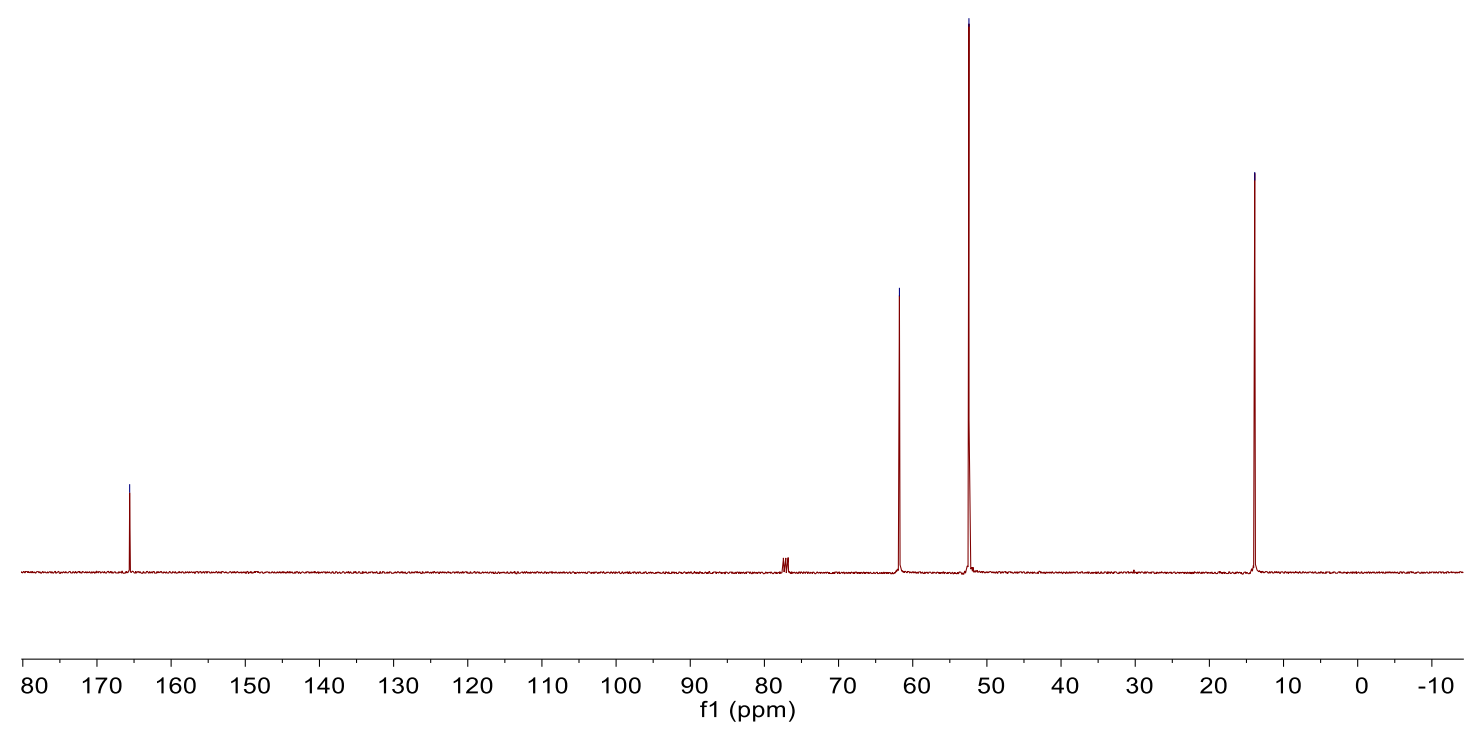

3-Hydroxy-9a,11b-dimethyltetradecahydrocyclopenta[1,2]phenanthro[8a,9-b]oxiren-9(2H)-one

(2u)
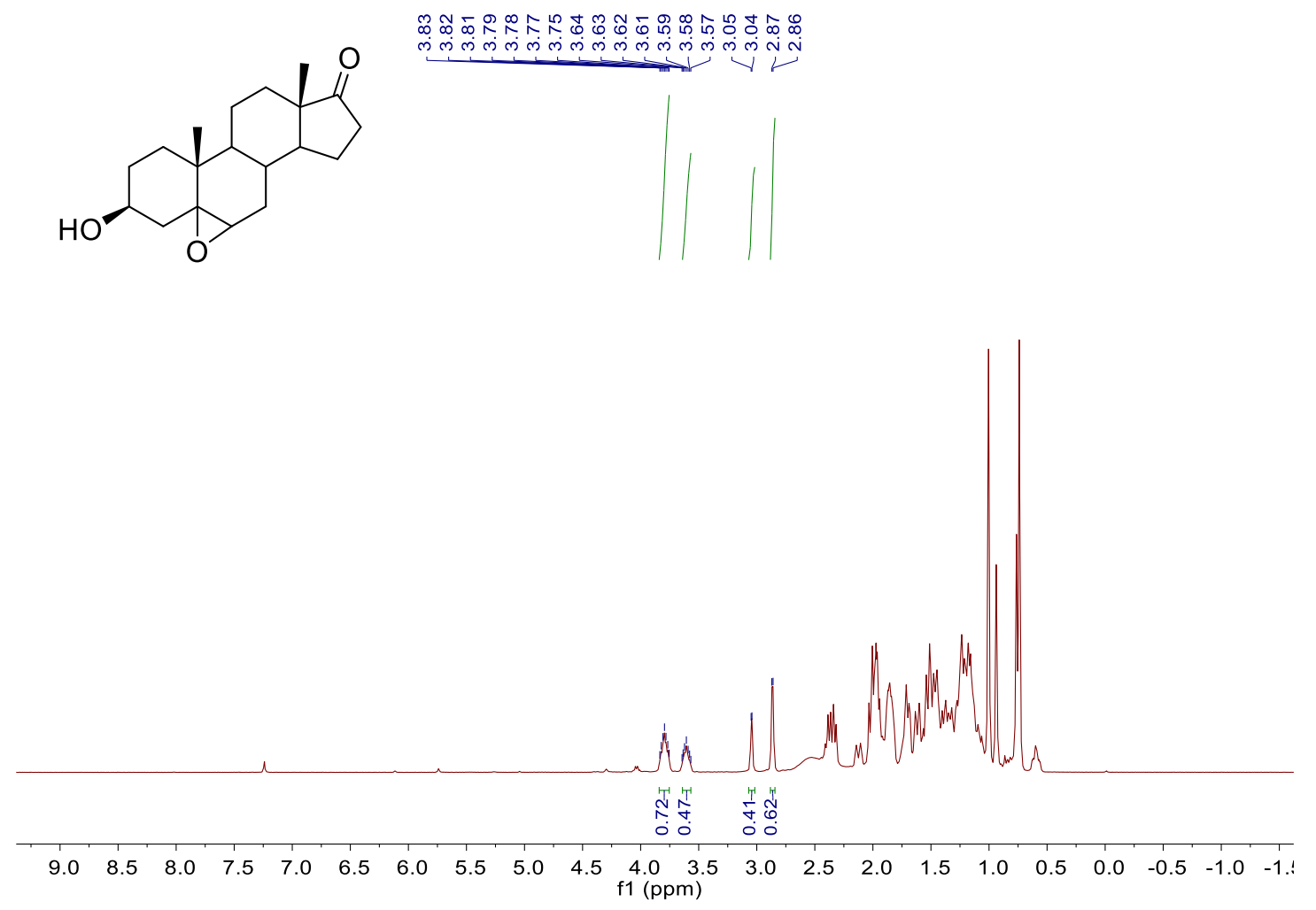
<smiles>CC12C(=O)CCC1C1CCC(=O)C3CC1C1(C[C@H](O)CC[C@@]12C)O3</smiles>

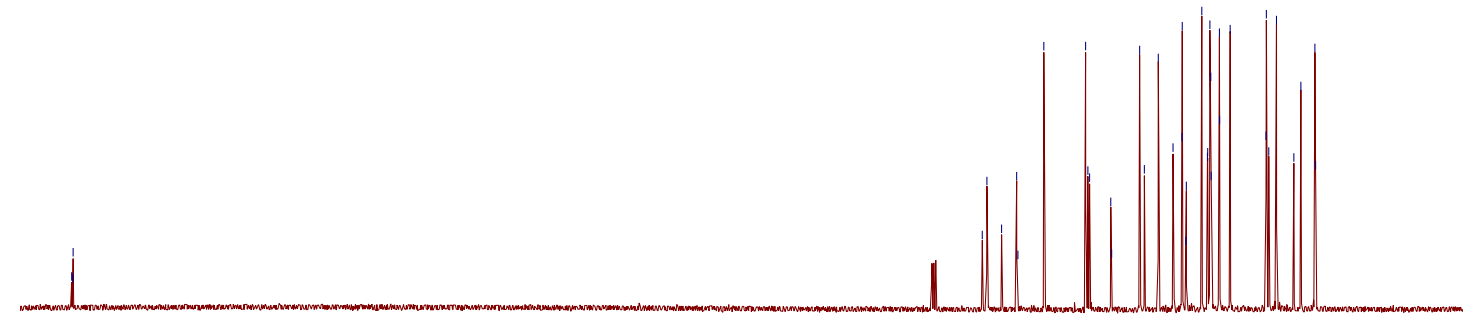

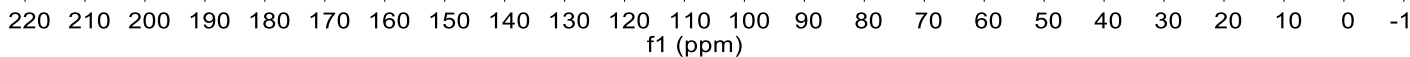

9a,11b-Dimethyl-9-(6-methylheptan-2-yl)hexadecahydrocyclopenta[1,2]phenanthro[8a,9-b]oxiren $-3-\mathrm{ol}(\mathbf{2 v})$

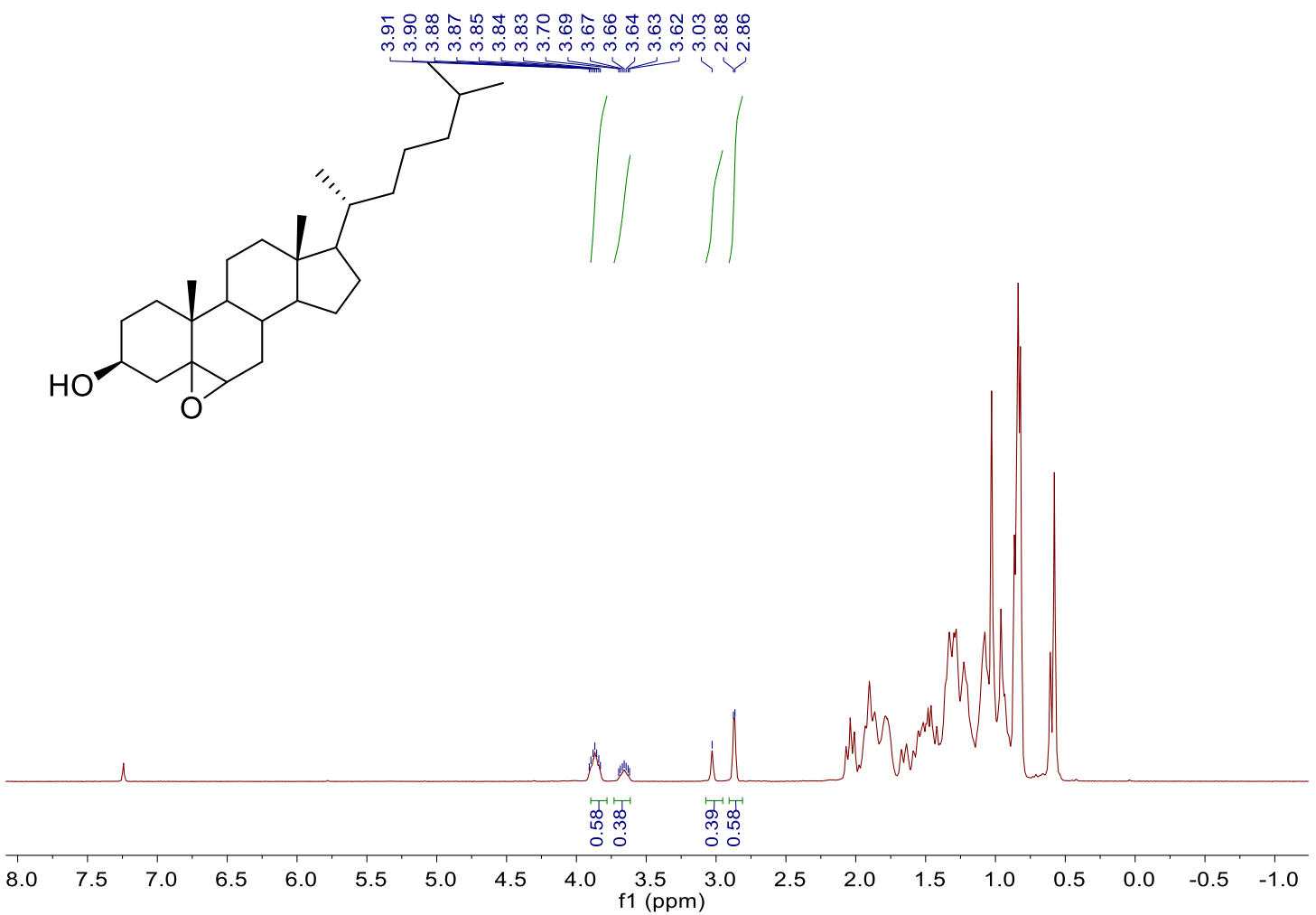




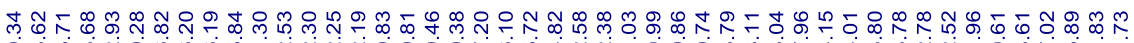
ஜ்
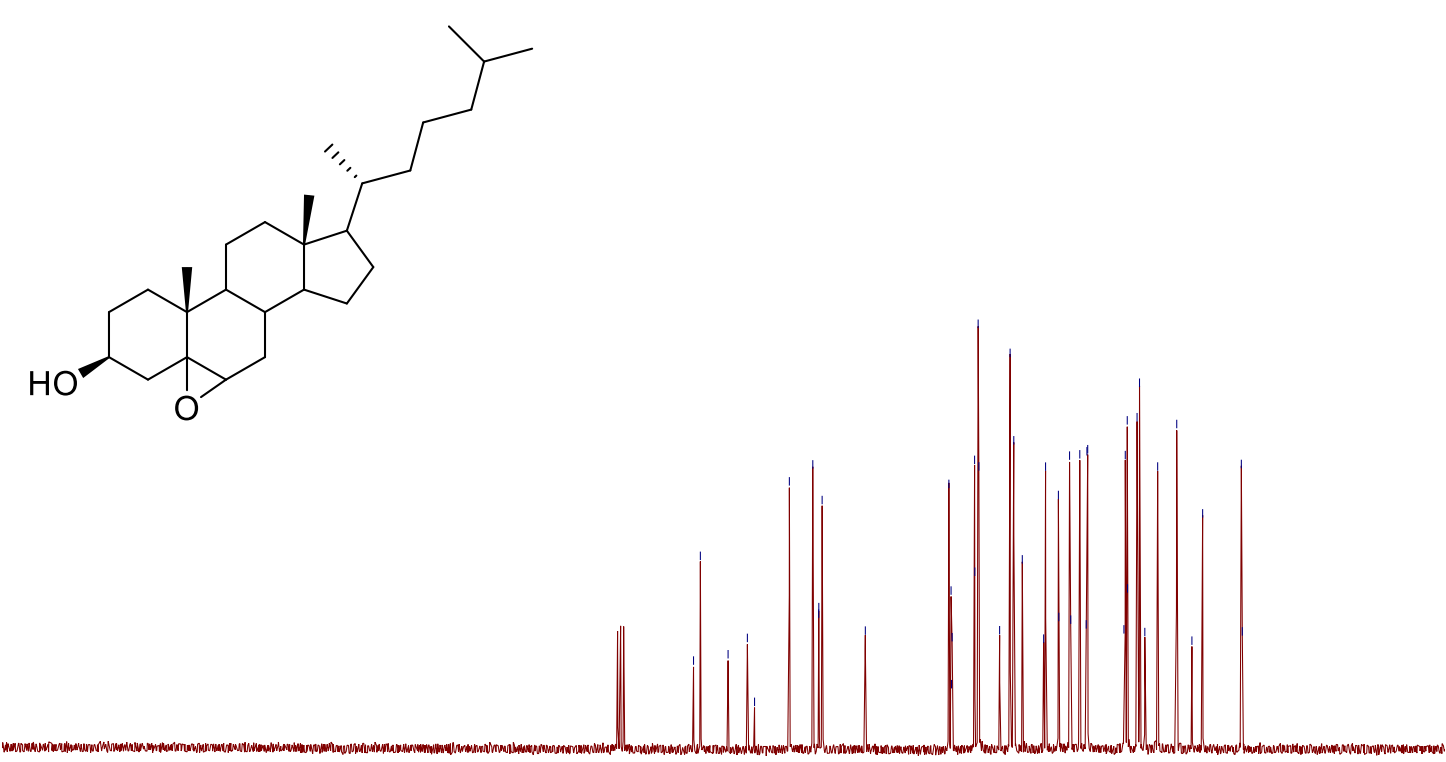

$\begin{array}{llllllllllllllllll}135 & 125 & 115 & 105 & 95 & 85 & 75 & \begin{array}{c}65 \\ \mathrm{f} 1(\mathrm{ppm})\end{array} & 55 & 45 & 35 & 25 & 15 & 5 & -5\end{array}$

5-(3,3-dimethyloxiran-2-yl)-3-methylpentanal (2w)

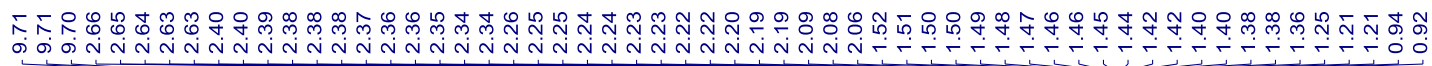<smiles>CC1CCC(C(C)(C)C)C(=O)C1</smiles>
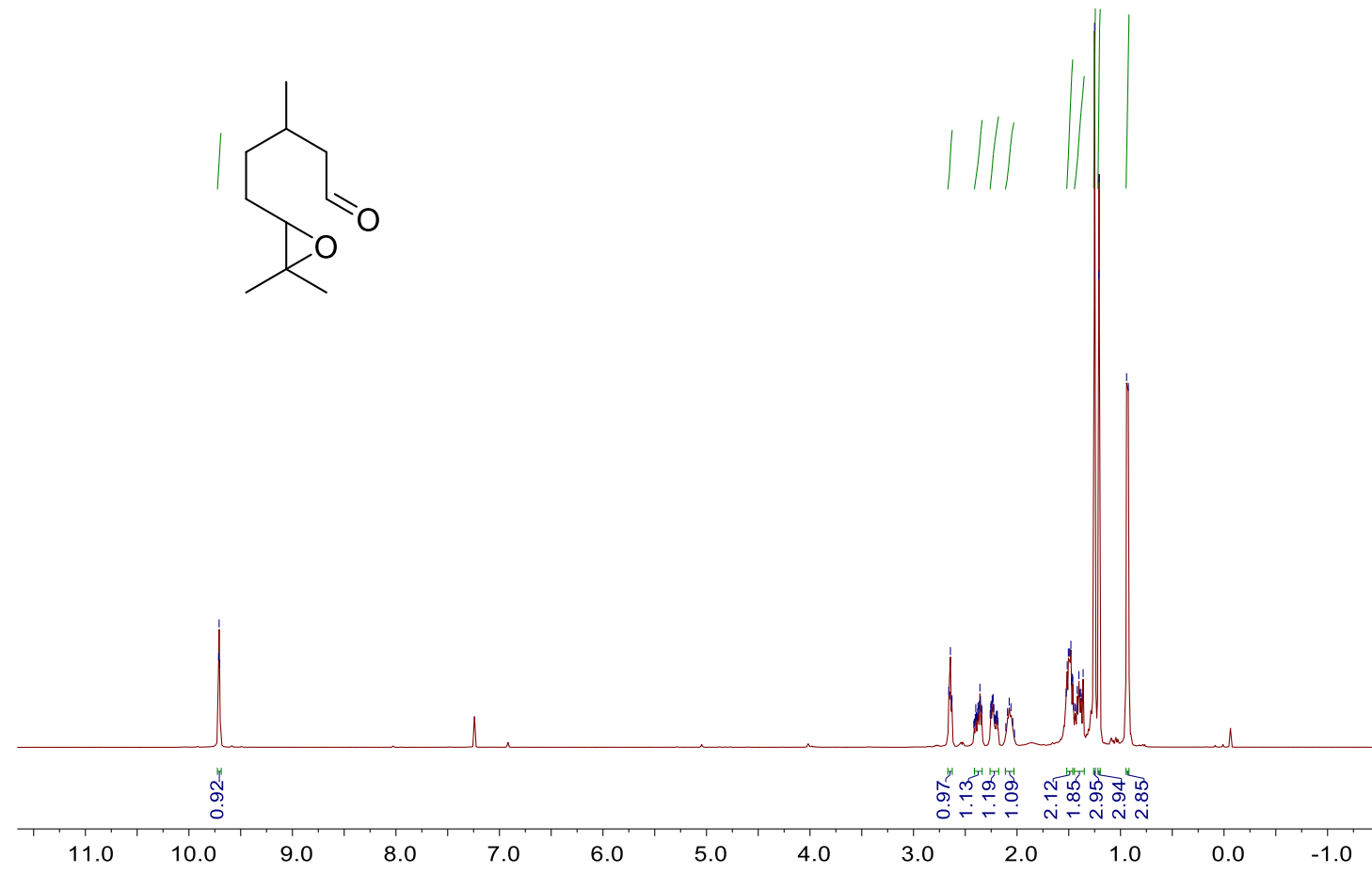
กิ

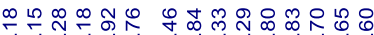

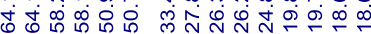

กั่<smiles>CC(CC=O)CCC1OC1(C)C</smiles>

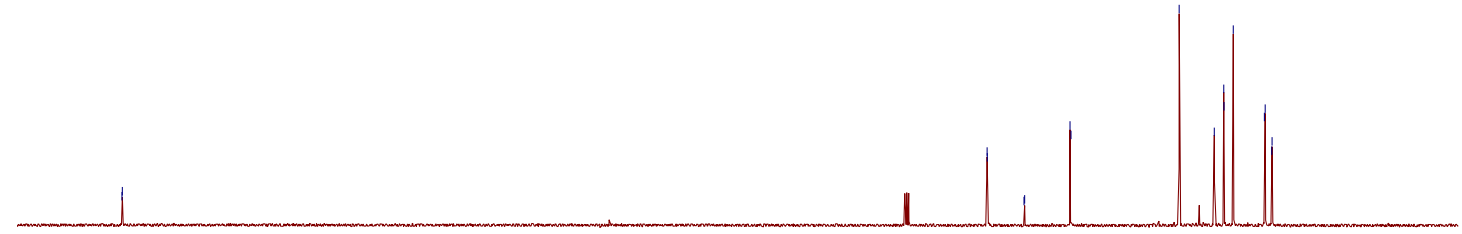

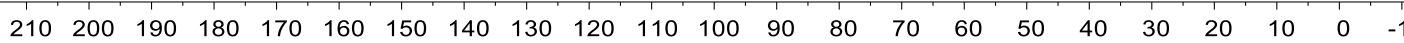

(Pent-4-en-1-ylsulfonyl)benzene (2x)

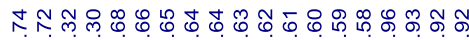

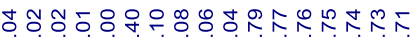

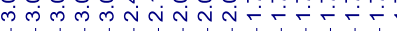

作
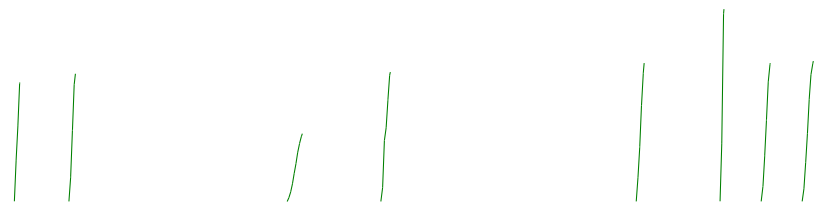<smiles>C=CCCCS(=O)(=O)c1ccc(C)cc1</smiles>

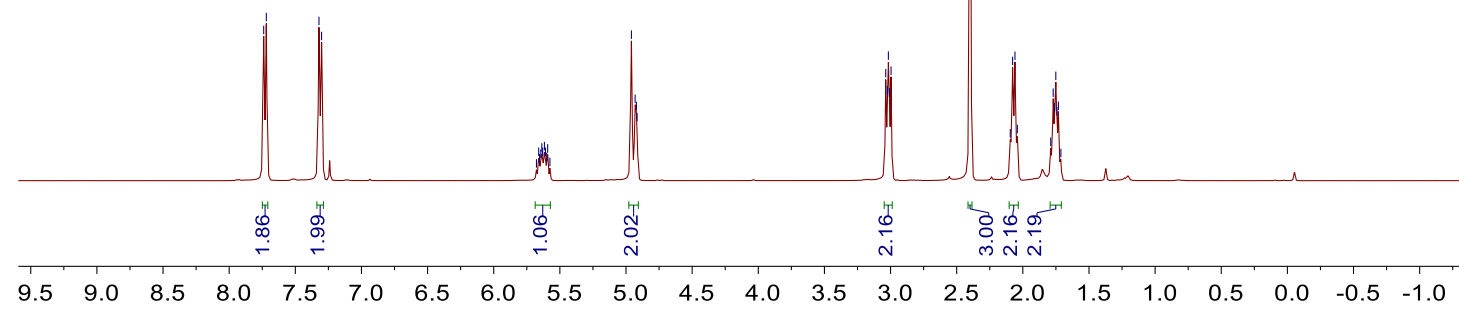




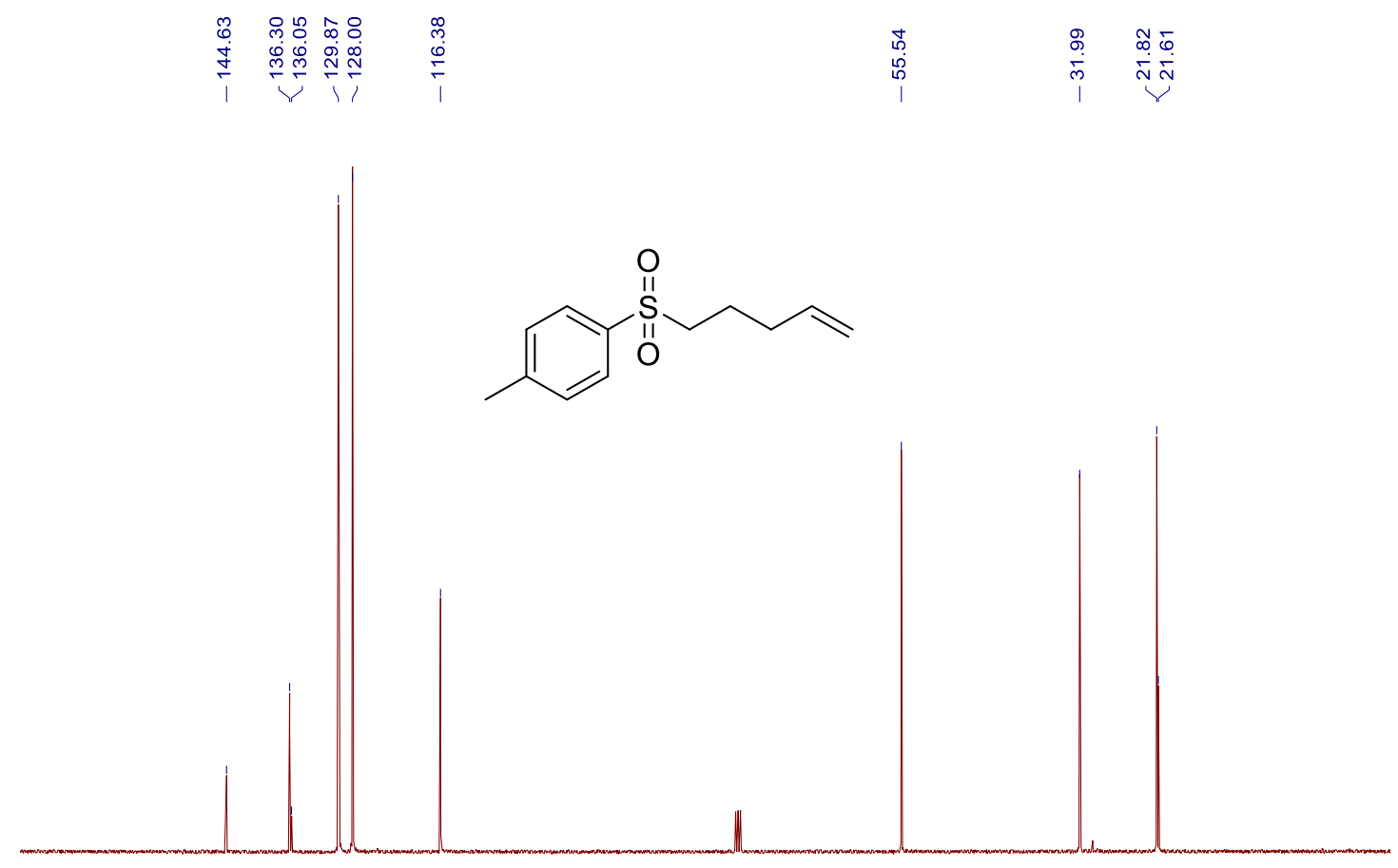

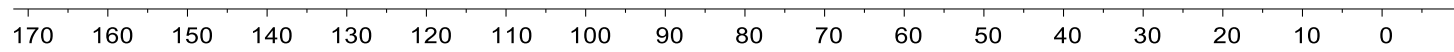

$N, N$-Dimethylaniline oxide (2y)
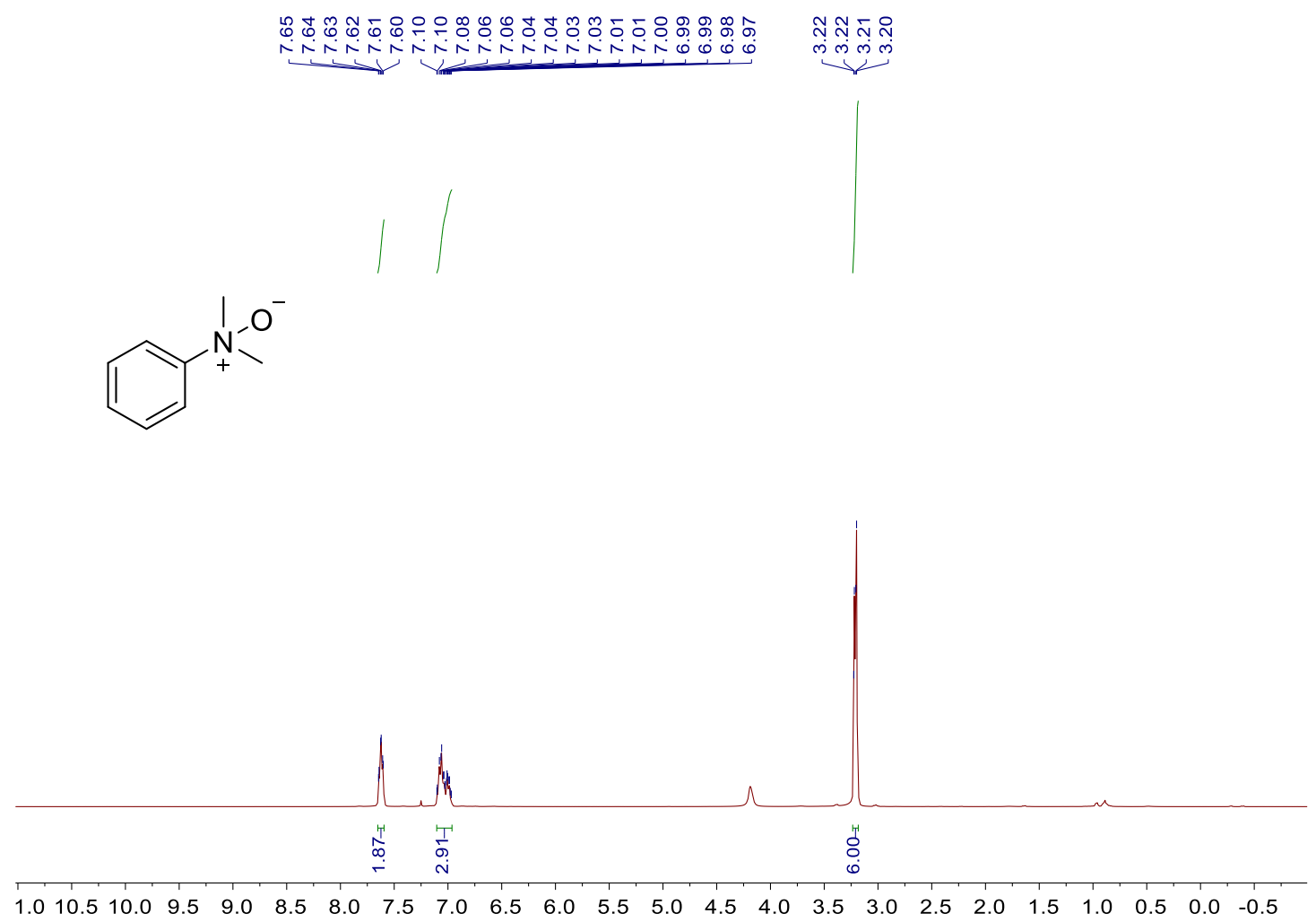


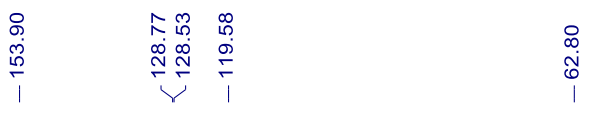<smiles>C[N+](C)([O-])c1ccccc1</smiles>

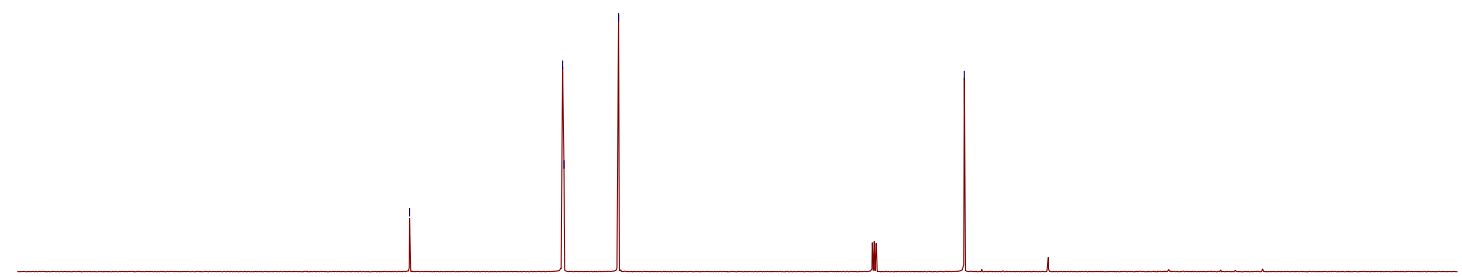

$\begin{array}{lllllllllllllllllllllll}210 & 200 & 190 & 180 & 170 & 160 & 150 & 140 & 130 & 120 & 110 & 100 & 90 & 80 & 70 & 60 & 50 & 40 & 30 & 20 & 10 & 0 & -10\end{array}$ 